\title{
Cognitive ability and education: how behavioural genetic research has advanced our knowledge and understanding of their association
}

\author{
Margherita Malanchini1,2,3, Kaili Rimfeld2, Andrea G. Allegrini2, Stuart J. Ritchie2, \& Robert Plomin2
}

1 Department of Biological and Experimental Psychology, Queen Mary University of London, United Kingdom. 2 Social, Genetic and Developmental Psychiatry Centre, Institute of Psychiatry, Psychology and Neuroscience, King's College London, United Kingdom.

3 Population Research Center, The University of Texas at Austin, United States.

Correspondence: Margherita Malanchini, Department of Biological and Experimental Psychology, Queen Mary University of London, Office 2.02, G.E. Fogg Building, Mile End Road, London E1 4NS. E-mail: m.malanchini@qmul.ac.uk

\begin{abstract}
Cognitive ability and educational success predict positive outcomes across the lifespan, from higher earnings to better health and longevity. The shared positive outcomes associated with cognitive ability and education are emblematic of the strong interconnections between them. Part of the observed associations between cognitive ability and education, as well as their links with wealth, morbidity and mortality, are rooted in genetic variation. The current review evaluates the contribution of decades of behavioural genetic research to our knowledge and understanding of the biological and environmental basis of the association between cognitive ability and education. The evidence reviewed points to a strong genetic basis in their association, observed from middle childhood to old age, which is amplified by environmental experiences. In addition, the strong stability and heritability of educational success are not driven entirely by cognitive ability. This highlights the contribution of other educationally relevant noncognitive characteristics. Considering both cognitive and noncognitive skills as well as their biological and environmental underpinnings will be fundamental in moving towards a comprehensive, evidence-based model of education.
\end{abstract}

Keywords: cognitive ability; academic performance; noncognitive skills; behavioural genetics; education 
Education is one of the major investments undertaken by contemporary society and the level of educational attainment has been steadily increasing worldwide (OECD, 2018). Educational attainment is a measure of human capital and is indicative of the skills of a population. As countries' economies gradually shift away from mass production towards becoming knowledge economies, governments are eager to increase the skills and welfare of the population through educational attainment (OECD, 2018). Higher levels of educational attainment are associated with higher employment rates, better job prospects and higher earnings (Furnham \& Cheng, 2016; Oreopoulos \& Salvanes, 2011; Ritchie \& Bates, 2013).

The positive life outcomes associated with educational attainment extend far beyond wealth and professional success, to include physical and mental health, wellbeing and even longevity (Cutler \& LlerasMuney, 2012; Montez \& Hayward, 2014). Similar long-term positive associations with health and wealth are observed for general cognitive ability: higher cognitive skills have been linked to higher earnings (Daly, Egan, \& O'Reilly, 2015; Kalechstein, Newton, \& van Gorp, 2003), better physical and mental health (Batty, Deary, \& Zaninotto, 2016; Baune et al., 2010; Latvala, Kuja-Halkola, D’Onofrio, Larsson, \& Lichtenstein, 2016; Mollon, David, Zammit, Lewis, \& Reichenberg, 2018; Snyder, Miyake, \& Hankin, 2015) and lower mortality (Deary, Weiss, \& Batty, 2010). The shared positive life outcomes associated with cognitive ability and educational attainment are likely to be intrinsically linked via the strong connection between these two traits. Indeed, extant research has identified general cognitive ability as the major source of variation in academic performance, measured as both school achievement and how long people spend in education -i.e. educational attainment (Krapohl et al., 2014; Mackintosh \& Mackintosh, 2011).

Part of the observed associations between cognitive ability and education, as well as their links with wealth, morbidity and mortality, are rooted in genetic variation. Converging evidence from decades of twin research and, more recently, molecular genetic studies has shown that general cognitive ability and educational attainment are heritable, highly polygenic, and that shared genetic factors account for part of their observed covariation (Deary, Harris, \& Hill, 2019; Hill et al., 2018; Lee et al., 2018; Plomin \& Von Stumm, 2018; Rimfeld et al., 2018; Tucker-Drob \& Briley, 2014). While there are several parallels in the development and manifestations of cognitive ability and educational attainment, emblematic of which is their close association across the lifespan, there are also key distinctions that characterize the development, origins and expression of both traits.

The aim of the current work is to review and evaluate how genetic research has contributed to furthering our knowledge and understanding of the associations between cognitive ability and education during 
development. We discuss the copious amount of knowledge that has emerged from behavioural genetic studies of cognitive and educational skills and their links. First, we review the wealth of research that has applied classical twin design to examine the origins of the associations between cognitive ability and academic performance (i.e. academic achievement and educational attainment). We highlight similarities as well as differences in the aetiology and developmental profiles that characterize these two broad dimensions. Second, we examine how molecular genetic research, particularly recent cutting-edge advances in DNA-based methods, has furthered our knowledge and understanding of cognitive ability, academic performance and their association. At every stage we discuss the strengths and limitations of applying each methodological approach to the investigation of individual differences in human behaviour and cognitive ability. Third, given that education extends beyond academic performance, we briefly widen our focus to discussing research on the association between cognitive ability, academic performance and other important educationally relevant 'noncognitive' traits. We conclude by discussing gaps in the current state of knowledge and future directions. In particular, we evaluate how the knowledge that has emerged from behavioural genetic research can help the field of education moving towards a more comprehensive, biologically oriented model of individual differences in cognitive ability and learning.

\section{Measuring general cognitive ability and academic performance}

Success in education has traditionally been closely associated with general cognitive ability. The first test of general cognitive ability (Binet, 1905) was developed with the aim of predicting individual differences in educational outcomes, which remains one of the main targets of cognitive tests to date (Deary, Strand, Smith, \& Fernandes, 2007). Contemporary standardized tests of intelligence derive from this early measure and assess performance across multiple dimensions. For instance, each test featured in the most widely adopted intelligence test batteries for adults and children (e.g. the Wechsler Scale of Intelligence and the Wechsler Intelligence Scale for Children; Wechsler, 2003, 2011), measures a specific dimension of cognitive functioning. These specific dimensions of cognitive functioning include skills such as verbal ability, spatial ability, nonverbal reasoning, processing speed, and memory. Although separable, these dimensions have been shown to correlate with one another, thus resulting in a measure of general cognitive ability.

General cognitive ability, also termed intelligence or $g$, is a psychometric construct that emerged at the beginning of the twentieth century from observations that almost all cognitive abilities correlate substantially and positively (Spearman, 1904). In other words, individuals performing highly in one cognitive test are also likely to show good performance in other tests of cognitive abilities (Carroll, 1993). ' $g$ ' indexes this covariation observed between cognitive tests. One way of interpreting this factor is that it represents individual differences 
in the domain-general abilities to plan, learn, think abstractly, and solve problems, all skills that contribute to successful completion of cognitive tests (Deary, 2013). Spearman's $g$ factor correlates very strongly (> .80) with a $g$ factor derived from the first unrotated principal component across multiple cognitive tests and with the score obtained from a full-scale intelligence quotient (IQ) test (Ceci, 1991).

As such, in the current review we consider these three formats as measures of $g$. The $g$ factor is universally observed (Lubinski, 2004), is stable across the lifespan (e.g. $r=.63$ between $g$ scores taken at age 11 and again 68 years later; Deary, Whalley, Lemmon, Crawford, \& Starr, 2000), and predicts important life outcomes including wealth, morbidity and mortality. Although the developmental stability of $g$ increases sharply from mid-childhood (Tucker-Drob \& Briley, 2014), modest rank-based stability is observed from a very young age: $g$ measured in four-year-olds was found to correlate modestly ( .20) with $g$ a decade later, largely for genetic reasons (Arden, Trzaskowski, Garfield, \& Plomin, 2014).

Standardized tests have also been developed to assess academic performance. These tests measure performance in key academic skills such as reading fluency, reading comprehension, computational skills and problem solving (Kaufman, Reynolds, Liu, Kaufman, \& McGrew, 2012). It has been argued that standardized tests of academic achievement are an index of cognitive ability rather than a true measure of academic performance, and that classroom performance, in the form of as teacher assessments or cumulative grades, might constitute a more realistic assessment of academic performance (e.g. McCall, Evahn, and Kratzer, 1992; Kaufman et al., 2012). However, correlations between numerous standardized tests of academic abilities and non-verbal intelligence are estimated at .50 (Guez, Panaïotis, Peyre, \& Ramus, 2018), suggesting that these measures are not entirely alike. Furthermore, recent work examining the concordance between standardized exam scores and teacher assessments throughout compulsory education has highlighted the strong overlap between these two formats (correlations of > .70) and their comparable associations with further educational attainment (Rimfeld, Malanchini et al., 2019). Consequently, in the current review we consider both standardized tests of academic achievement and teacher assessments, in addition to educational attainment, as useful indices of academic performance.

\section{Psychological research into the association between cognitive ability and academic performance}

The observation that $g$ reliably predicts educational outcomes is a fascinating phenomenon that has been extensively studied in the literature. Taken at any point across development, $g$ shares a moderate to strong correlation with academic achievement, ranging from .40 to .80 (Meike Bartels, Rietveld, Van Baal, \& Boomsma, 2002; Ian J. Deary et al., 2007; Sternberg, Grigorenko, \& Bundy, 2007). A meta-analysis of 240 
independent samples including over 100,000 participants found a population correlation of .54 between intelligence and school grades; effect sizes were similar across subjects, ranging between .49 for mathematics and science and .41 for languages, with two exceptions: music (.19) and sports (.09) (Roth et al., 2015). The same meta-analysis showed that the magnitude of the correlation between intelligence and school grades increased with age, from .45 during the primary school years to .58 in high school, and effects were consistent across gender (Roth et al., 2015).

Strong associations between cognitive abilities and academic achievement have also been observed longitudinally. One of the largest prospective studies exploring the association between $g$ and academic achievement, including over 70,000 children from England, found that $g$ at age 11 correlated strongly with achievement at age 16 and predicted individual differences in every school subject, accounting for between 59\% of the variance in mathematics to $18 \%$ of the variance in Art and Design (Deary et al., 2007). Even more strikingly, tests of cognitive abilities taken very early in life are valid predictors of academic achievement and abilities later in development. Longitudinal investigations have found moderate associations between early cognitive skills and achievement several years later. $g$ measured at four years of age was found to predict individual differences in mathematics ability and achievement eight years later with moderate effect sizes (Malanchini et al., 2016). Similarly, another study found that non-verbal intelligence and working memory measured at age 5 correlated moderately $(r=.30-.40)$ with individual differences in literacy and numeracy six years later (Alloway \& Alloway, 2010).

The observed long-term predictive power of cognitive ability measured early in development suggests that $g$ might have a causal effect on academic performance over development (Watkins, Lei, \& Canivez, 2007). Studies have supported this proposition, finding for example that fluid intelligence ( $g f$ ) had a positive influence on academic achievement, particularly on quantitative abilities, and that this influence was stronger during childhood and early adolescence (Ferrer \& McArdle, 2004). However, the observed associations between early $g$ and later academic performance are likely to conceal reciprocal links: students with higher cognitive skills are likely to achieve better grades and consequently spend more time in education, but also spending more time in education fosters cognitive development.

A recent meta-analysis of the effects of education on cognitive ability including data from over 600,000 individuals supports the proposition that time spent in education exerts a positive causal effect on the development of cognitive skills (Ritchie \& Tucker-Drob, 2018). Leveraging quasi-experimental designs (i.e. longitudinal studies, compulsory policy changes and regression discontinuity), the meta-analysis found that the effect of one additional year in education corresponded to gains of between 1 and 5 standardized IQ points, 
depending on the design considered. These gains in cognitive ability elicited by additional time spent in education were observed for a general cognitive ability composite as well as when tests of fluid and crystallized intelligence were considered separately. Furthermore, the effects persisted across the lifespan (Ritchie \& Tucker-Drob, 2018). These findings are in line with those of an earlier review (Ceci, 1991).

In line with Spearman's proposition of a domain-specific effect of education on cognitive skills (Spearman, 1927), another study found that the improvements associated with longer time spent in education were observed for specific cognitive abilities rather than for $g$ (Ritchie, Bates, \& Deary, 2015). In addition, education was found to have a beneficial impact on intelligence in old age, and particularly so for individuals scoring lower on an IQ test in childhood, but no effect on lower-level cognitive abilities such as processing speed (Ritchie, Bates, Der, Starr, \& Deary, 2013). These findings point to the importance of examining domaingeneral as well as domain-specific effects of the association between cognitive ability and academic performance - note that there were too few studies examining domain-specificity for a useful meta-analysis to be performed on this question.

Surprisingly few studies have examined the reciprocal links between $g$ and academic achievement over multiple developmental stages applying formal longitudinal designs (Deary \& Johnson, 2010). One such study found that cognitive ability measured in early childhood predicted achievement in reading and mathematics and, in turn, mathematics achievement in early adolescence predicted adolescent $g$ (McCoach, Yu, Gottfried, \& Gottfried, 2017). While this study included multiple measures of reading and mathematics achievement over development, $g$ was only assessed once before the start of schooling and once in adolescence, preventing conclusions on the reciprocal effects of $g$ on achievement and vice versa over a more fine-grained time scale. Evidence for the positive effect of reading on cognitive development comes for a study observing that reading comprehension contributed to growth in verbal ability over and above general cognitive ability from age 8 to 16 (Cain \& Oakhill, 2011). A further study applied cross-lagged panel analysis to examine the reciprocal links between achievement in reading and mathematics and $g$ measured at three ages during primary school, providing evidence for reciprocal influences (Cowan, Hurry, \& Midouhas, 2018).

Therefore, cognitive ability and academic performance share a substantial, reciprocal association that emerges early in development. But what are the biological and environmental mechanisms underlying this association? Behavioural genetic research has investigated the origins of individual differences in cognitive abilities and academic performance, and of their links, across the lifespan applying multiple methodologies. In the sections that follow we begin by reviewing and evaluating evidence from several decades of twin studies before moving on to examine recent evidence from molecular genetic research. 


\section{Twin studies of the genetic and environmental underpinnings of cognitive ability, academic performance and}

their association.

Studies using genetically informative methodologies have explored the origins of individual differences in general cognitive ability and of its well-established association with academic performance. Indeed, investigating why individuals differ in their cognitive skills has been one of the main interests of behavioural genetic research (Plomin \& Deary, 2015). The relative contribution of genetic and environmental factors to variation in a trait has been classically estimated using twin and family studies (Polderman et al., 2015).

The twin method: A brief overview

Twin design capitalizes on the genetic relatedness between different types of twin pairs to estimate the extent to which differences between individuals in a given trait are accounted for by genetic and environmental factors. The method is grounded in the fact that monozygotic twins share one hundred percent of their genetic makeup, and dizygotic twins share on average fifty percent of the genes that differ between individuals. Furthermore, the method makes the key assumption that both types of twins who are raised in the same family home share their rearing environments to approximately the same extent (Conley, Rauscher, Dawes, Magnusson, \& Siegal, 2013; Kendler, Neale, Kessler, Heath, \& Eaves, 1993). By comparing how similar monozygotic and dizygotic twins are for a given trait, it is possible, under these assumptions, to calculate the extent to which differences between individuals in that population at that particular time are due to genetic and environmental influences.

The twin method estimates the relative contribution of three main sources of variation in the population: heritability, shared environment and nonshared environment. Heritability describes the amount of variance in a trait that can be attributed to genetic differences in a given population, and can be roughly estimated by doubling the difference in the correlation between the monozygotic and dizygotic twin pairs (Martin \& Eaves, 1977). Shared environment describes the extent to which twins raised in the same family resemble each other beyond their genetic similarity. Finally, non-shared environment describes environmental variance that does not contribute to similarities between twin pairs, which in formal structural equation models can also incorporate measurement error.

Twin studies of the genetic and environmental underpinnings of general cognitive ability and academic performance 
Research applying the twin design has consistently shown that genetic differences between individuals play an important role in explaining variation in $g$. The heritability of $g$-the extent to which genetic differences between individuals explain differences in their observed cognitive performance- has been found to increase substantially from early childhood to adulthood. Genetic factors were found to explain around $20 \%$ of individual differences in $g$ in infancy, around $40 \%$ in late childhood, and about $60 \%$ of the variation in $g$ in adolescence and adulthood (Haworth et al., 2010), and to reach approximately 80\% in older adulthood (Plomin $\&$ Deary, 2015). The observation of a linear increase in the heritability of $g$ over development has been replicated across numerous samples cross-culturally (Tucker-Drob, Briley, \& Harden, 2013).

Two main theoretical accounts, not mutually exclusive, have been proposed as potential explanations for the observed increase in the heritability of $g$ over development. The first sees transactional models (TuckerDrob \& Briley, 2014; Tucker-Drob et al., 2013), rooted in gene-environment correlation (Plomin, DeFries, \& Loehlin, 1977), as the main mechanism through which children experience, evoke, select and consolidate their genetic propensity through environmental experiences, resulting in amplified genetic effects on cognitive ability (Tucker-Drob et al., 2013).

Gene-environment correlation describes the processes through which individuals experience environments that correlate with their genotype, rather than being exposed to random environmental experiences. This can happen through three mechanisms. First, passive processes: children and adolescents tend to grow up with their parents who shape the raring environment on the basis of their own genotype, which they share with their offspring. Second, evocative processes: individuals may elicit their experiences on the basis of their partly genetically influenced traits, such as dispositions and characteristics. Third, active processes: individuals actively select and modify their experiences based on their genetic propensities, dispositions and appetites (Plomin et al., 1977; Plomin, 2014).

An alternative account proposes that novel genetic influences might come into play over development and result in the observed increased in the heritability of cognitive ability. Novel genetic influences on cognitive ability were found to come into play early in development, before middle childhood (Tucker-Drob \& Briley, 2014). At the same time, strong genetic stability, indexed by substantial genetic correlation $(r \mathrm{~A})$, has been observed in $g$ from age 7 to age $12\left(r_{\mathrm{A}}=.75\right)$, as well as between $g$ at age 11 and age $69\left(r_{\mathrm{A}}=.62\right.$; Deary et al., 2012), suggesting a greater role of transactional models in accounting for the increased heritability of $g$ over the lifespan (Tucker-Drob et al., 2013). 
Academic performance is also highly heritable. Studies found that genetic differences between people explain a substantial portion of their individual differences in academic achievement at every stage of compulsory education (Kovas et al., 2007; Shakeshaft et al., 2013; Tosto, Malykh, Voronin, Plomin, \& Kovas, 2013), as well as in standardized tests of academic abilities, such as for example reading and mathematics (Malanchini, Engelhardt, Grotzinger, Harden, \& Tucker-Drob, 2018; Malanchini et al., 2017; Petrill et al., 2012; Tosto et al., 2017; Tucker-Drob, Briley, Engelhardt, Mann, \& Harden, 2016). A meta-analysis of the relative contribution of genetic, shared environmental and nonshared environmental influences on academic achievement in primary school found evidence for the importance of genetic variation at all ages crossculturally (de Zeeuw et al., 2015).

Genetic differences between students have also been found to play a major role in students' choice of academic career beyond compulsory education, for example, A-level choice and achievement (Rimfeld, Ayorech, Dale, Kovas, \& Plomin, 2016). After compulsory education, students in the UK can choose to continue studying for two years in preparation for university, freely selecting the subjects they wish to focus on. At the end of these two years, students are required to take 'A-level' exams, which are fundamental for admission to university. Genetic factors were found to account not only for differences in A-level grades, but also for the choice of continuing on to A-levels and for specific subject choices (Rimfeld et al., 2016). Similarly, genetic factors were found to account for variation in several measures of educational attainment, including the choice of enrolling in an undergraduate degree and university success (Smith-Woolley, Ayorech, Dale, von Stumm, \& Plomin, 2018).

Different developmental trajectories characterize the aetiology of $g$ and academic performance

It is reasonable to assume that the high heritability of academic achievement observed at every stage in development is largely explained by its robust association with $g$. However, this proposition is not in line with evidence showing that academic achievement in literacy and numeracy in early and mid-childhood is significantly more heritable than $g$ (Kovas et al., 2013). As the heritability of $g$ increases over development (Plomin \& Deary, 2015), by early adolescence $g$ and achievement show comparable heritabilities. The difference in the heritability of $g$ and achievement in the early school years lessens the plausibility of the proposition that genetic variation in $g$ is the major source underlying the high heritability of academic achievement. An even stronger line of evidence for the high heritability of academic achievement, independent of $g$, comes from a recent large-scale longitudinal investigation of the genetic and environmental stability of academic achievement over compulsory education in the United Kingdom (Rimfeld, Malanchini et al., 2018). 
Applying a longitudinal twin design, the study showed that academic achievement is highly stable over compulsory education and its stability is largely due to genetic influences even after accounting for $g$ (Rimfeld, Malanchini et al., 2018). Although genetic innovation was observed at every stage, indicating new genetic effects coming into play, these effects were not specific to each developmental stage, instead they were passed on to the following developmental stages.

Research examining the continuity of genetic and environmental influences on $g$ over development also reports strong genetic stability, as largely the same genetic effects are found to contribute to variation in cognition over the lifespan. Results of a meta-analysis of 21 studies from 15 independent samples from early childhood to older adulthood showed that the stability of $g$ increases sharply from early to middle childhood and remains high throughout the lifespan (Tucker-Drob \& Briley, 2014). Coupled with a sharp increase in stability observed around age 7, the meta-analysis observed shifts in the extent to which genetic and environmental influences contributed to the covariation between measures of $g$ over time. Shared environment played a significant role in explaining early stability, but its contribution was greatly reduced nearly to zero in late adolescence. On the contrary, genetic factors accounted for a small proportion of the stability of early $g$, but their contribution increased sharply during middle childhood and remained stable throughout adolescence and adulthood (Tucker-Drob \& Briley, 2014). This is in line with earlier evidence on the genetic stability of intelligence from age 5 to 12 in a Dutch sample (Bartels, Rietveld, Van Baal, \& Boomsma, 2002). Finally, the contribution of nonshared environmental influences to the stability of $g$ was negligible throughout childhood and adolescence, but increased to moderate during adulthood (Tucker-Drob \& Briley, 2014).

The findings are consistent with those observed for academic achievement over compulsory education, particularly when considering that schooling was measured over four waves from the age of 7 to the age of 16 (Rimfeld, Malanchini, et al. 2018). Over this developmental time, the stability of both academic achievement and $g$ is mostly due to genetic variation, with shared environmental variation playing a modest role and nonshared environment having a negligible effect (Rimfeld, Malanchini et al., 2018; Tucker-Drob \& Briley, 2014). Studies that have examined the stability of academic achievement (Luo, Haworth, \& Plomin, 2010) and of specific academic abilities, including reading comprehension (Malanchini et al., 2017), teacher ratings of reading ability (Harlaar, Dale, \& Plomin, 2007) and teacher ratings of mathematics ability (Luo, Kovas, Haworth, \& Plomin, 2011) over a shorter time span provide support for the central role of genetic variation.

Therefore, as represented in Figure 1, the phenotypic stability of both $g$ and academic achievement increases modestly from mid-childhood to late adolescence (e.g. Roth et al., 2015) and is largely accounted for by genetic factors. Shared environmental influences account for a much lower proportion of the covariance 
between measures over time, amounting to about one third of the magnitude of genetic effects when considering academic achievement (Rimfeld, Malanchini et al., 2018). Nonshared environments are largely specific to each measurement occasion and do not contribute consistently to the stability of achievement and $g$ from childhood to late adolescence and emerging adulthood. The same pattern of results is observed for different academic domains and does not seem to be explained by the association between $g$ and achievement, as the phenotypic and genetic stability of achievement remained high even after statistically accounting for $g$ (Rimfeld, Malanchini et al., 2018). This suggests that several other - partly genetically influenced-factors contribute to the genetic stability in academic achievement beyond $g$ (Krapohl, Rimfeld et al., 2014; Malanchini et al., 2018). This will be discussed in more detail below.

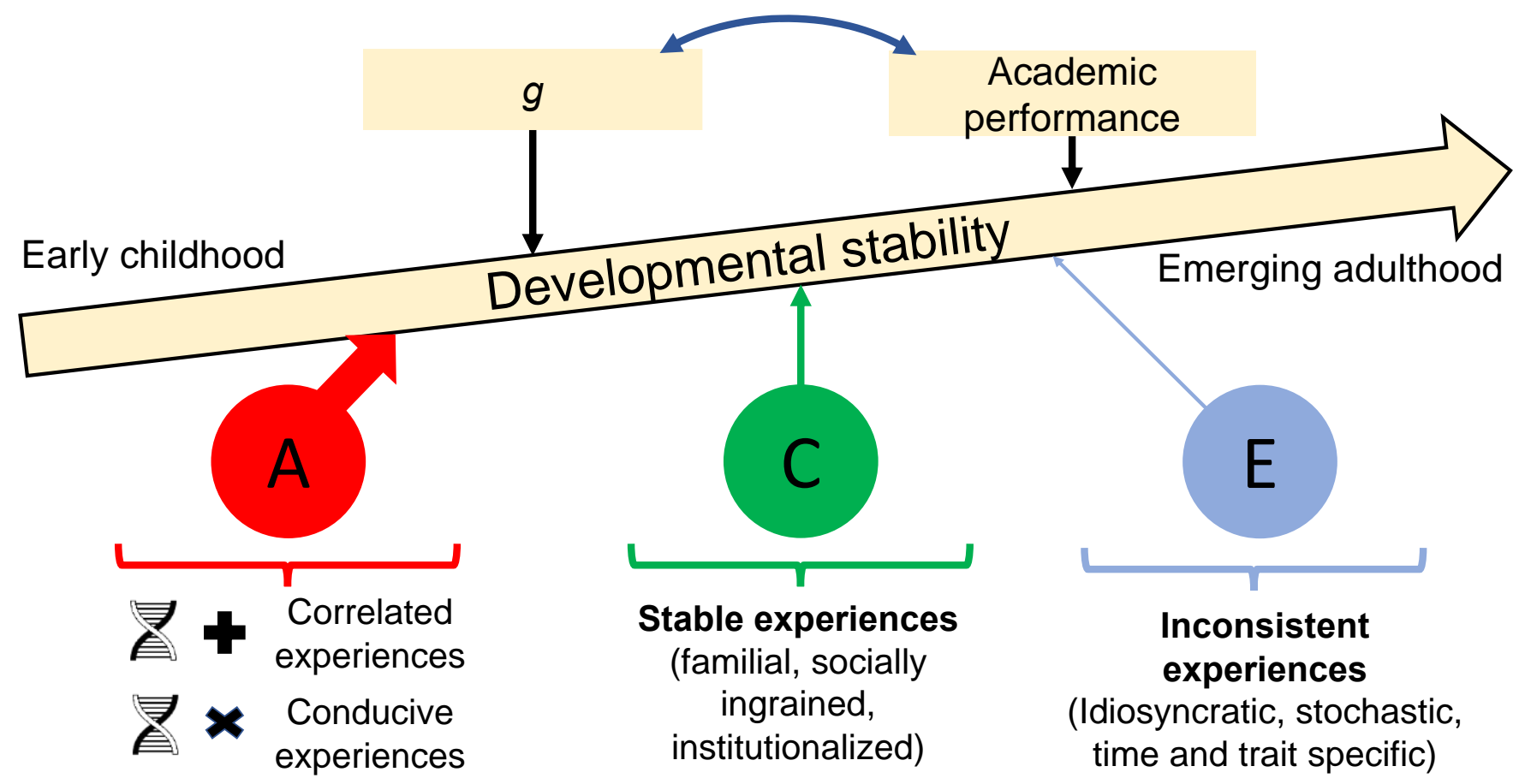

Figure 1. How genetic (A), shared environmental (C) and nonshared environmental (E) factors play different roles in accounting for the stability of $g$, academic performance and of their association over development. Genetic influences, which can encompass geneenvironment interplay (correlations and interactions), account for the majority of the observed developmental stability. Shared environmental factors, likely to be stable experiences, are consistently found to account for a lesser part of the developmental stability. On the other hand, non-shared environmental factors are rarely observed to be implicated in the stability of $g$ and academic performance over childhood and adolescence, indicating that their influences are mostly unsystematic. 
Twin studies of the association between general cognitive ability and academic performance: pleiotropic effects are observed throughout development

The association between academic performance and $g$ is also stable over development and twin research has shown that genetic factors explain a substantial portion of their links across the lifespan (Calvin et al., 2012; Johnson, Deary, \& Iacono, 2009). In one of the first investigations into the genetic and environmental underpinnings of the covariation between cognitive ability and academic performance, Thompson, Detterman and Plomin (1991, p. 164) state: '...the covariance between ability and achievement is primarily genetically determined ... ability-achievement discrepancies are due to environmental differences.' (Thompson, Detterman, \& Plomin, 1991). Over the following nearly three decades numerous studies have supported this general conclusion about the association between cognitive ability and academic performance.

Strong correlations between $g$ and academic performance are observed when considering both standardized tests of academic abilities - e.g. reading comprehension and mathematics computation abilities (Harlaar, Hayiou-Thomas, \& Plomin, 2009) as well as for more general measures of academic performance such as exams scores and teacher grades (Kovas et al., 2007). In the same way that the associations between $g$ and reading, and $g$ and mathematics, are characterized by comparable moderate effect sizes ( .40), the proportion of their correlation that is accounted for by genetic and environmental factors is substantial for both academic domains (Kovas, Harlaar, Petrill, \& Plomin, 2005). The proportion of the phenotypic correlation that is due to genetic factors is known as the bivariate heritability, and it is also possible to calculate bivariate estimates for the shared and nonshared environments. In a sample of nearly 6,000 7-year-old twins, the bivariate heritability observed for $g$ and mathematics was .83 and that for $g$ and reading .65 , with partly overlapping confidence intervals around the estimates, indicating that genetic factors accounted for over $60 \%$ of the correlation between $g$ and academic achievement in different domains. Shared environment accounted for $27 \%$ of the correlation between $g$ and reading and $9 \%$ of that between $g$ and mathematics. Nonshared environment accounted for $8 \%$ of the correlation between $g$ and both academic subjects (Kovas et al., 2005).

Substantial pleiotropic effects, indexed by the genetic correlation between traits, were observed between academic achievement in all domains and $g$ (.44-.69; Rimfeld, Kovas, Dale, \& Plomin, 2015). Pleiotropy (genes influence multiple traits; Lynch \& Walsh, 1998) between $g$ and academic achievement is not specific to middle childhood and adolescence but observed consistently across development. Findings from a study leveraging whole population cohorts across two countries, the United Kingdom and the Netherlands, provide general support for the substantial role of genetic covariance in accounting for the observed correlation between $g$ and academic achievement (Calvin et al., 2012). Moreover, pleiotropic effects between $g$ and achievement 
have been observed longitudinally between early $g$ and mathematics achievement at age 12 (Malanchini et al., 2016).

Therefore, a substantial part of the genetic variance accounting for individual differences in $g$ is also implicated in academic performance. The notion that partly overlapping genes contribute to individual differences in all aspects of cognitive ability and learning is summarized by the 'generalist genes' account of learning abilities and disabilities (Plomin \& Kovas, 2005). The theory, grounded in the two notions of pleiotropy (one gene affects many traits) and polygenicity (several genes influence one trait), proposes that genetic influences on different cognitive and academic abilities and disabilities overlap. Although this account emerged largely as a function of findings from twin studies (Davis et al., 2008; Kovas et al., 2005), more recent studies applying molecular genetic methods have provided support for the general effects of the genes implicated in cognitive ability and academic achievement (Bulik-Sullivan et al., 2015; Lee et al., 2018; Rimfeld et al., 2015; Maciej Trzaskowski et al., 2013).

Although the substantial genetic overlap between cognitive and educational phenotypes is consistent with widespread pleiotropy between multiple educationally relevant and cognitive traits, it is possible that alternative biological mechanisms may underlie their covariation. Indeed, the observed genetic correlations might reflect genetic causality, whereby genetic factors influence one trait, for example $g$, and in turn $g$ influences another trait, for example academic performance (Ligthart \& Boomsma, 2012). Longitudinal genetically-informative models, such as for example cross-lagged panel analyses (Malanchini et al., 2017) will be able to shed light on the mechanisms supporting the nearly ubiquitous pattern of genetic associations observed across multiple aspects of cognitive ability and educational achievement. Research that has applied this methodology in the context of education, focusing on the association between academic performance and motivation, provides support for the existence of both mechanisms. The study found that reading achievement and motivation correlated substantially for genetic reasons (supporting pleiotropic mechanisms). In addition, the two traits mutually influenced each other longitudinally, and these reciprocal links were partly genetic in origin (supporting genetic causality; Malanchini et al., 2017). However, no research to date has applied this type of design to the investigation of the associations between cogntive ability and academic performance over development.

The role of individual-specific and family-wide environmental factors

Other studies have focused on examining the role of environmental influences on cognitive ability and academic performance over time applying genetically informative longitudinal methods. One such study 
leveraged monozygotic twin differences with a cross-lagged design to explore the role of nonshared environmental influences on the association between $g$ and academic performance (Ritchie, Bates, \& Plomin, 2015). Because monozygotic twins are genetically identical and grow up in the same home environment, the monozygotic twin differences design allows for the examination of environmental influences that are unique to each twin, free from the confounds of genetic and shared environmental effects (Vitaro, Brendgen, \& Arseneault, 2009). Examining discordances between monozygotic twin pairs in reading and $g$ longitudinally, this study found support for nonshared environmental effects on reading ability having a weak causal effect on $g$ at subsequent developmental stages. These results support the view that individual-specific environmental effects on reading ability are partly stable over time and transfer to more general cognitive skills resulting in improved performance over development (Ritchie, Bates, \& Plomin, 2015). However, the use of a state-trait model, which accounts more strongly for the phenotypic stability of reading and of intelligence, resulted in substantially lower estimates of the potential effects of reading ability on broader cognitive skills (Bailey $\&$ Littlefield, 2017).

Other studies have provided support for the role of shared environmental factors in accounting for the association between cognitive abilities and academic performance. As previously discussed, the role of shared environmental influences on the stability of $g$ and academic performance and of their developmental association is generally found to be small, particularly from mid-childhood. However, studies have found evidence for stronger effects, in early childhood (Lemelin et al., 2007) as well as in countries characterized by less standardized educational experiences (Petrill \& Wilkerson, 2000). Interestingly, although the proportion of the cross-sectional and longitudinal links accounted for by shared environmental influences (bivariate shared environmentality) is relatively small, shared environmental correlations between multiple measures of academic performance and cognitive abilities tend to be very strong, suggesting that shared environmental influences are translational across domains of cognitive ability and learning and are stable over time. For example, a recent meta-analysis of twin studies of the association between reading and mathematics abilities and disabilities found a meta-analytic estimate of .90 for the shared environmental correlation between reading and mathematics (Daucourt et al., 2019).

Assumptions and limitations of twin studies

The wealth of knowledge that has emerged from twin studies of cognitive ability, academic performance and their associations needs to be evaluated in light of the limitations that apply to the methodology. The twin method is based on several assumptions. First, the equal environments assumption is the idea that environmental similarity is the same for monozygotic and dizygotic twin pairs growing up in the same family 
(Knopik, Neiderhiser, Defries, \& Plomin, 2016). Studies have observed that monozygotic twins are more likely to share analogous environmental experiences than dizygotic twins: they tend to be treated more similarly and to more often share friends. Nevertheless, studies assessing the impact of sharing more environmental experiences did not find that this to have substantial influence on the degree of phenotypic concordance (Conley et al., 2013; Kendler, Kessler, Neale, Heath, \& Eaves, 1993).

A second assumption of the twin method is random mating: people are assumed to mate at random, and not with other people that resemble them. In reality this assumption is violated as people tend to mate with people who resemble them both phenotypically and genetically, a concept known as assortative mating (Ask, Idstad, Engdahl, \& Tambs, 2013) Assortative mating is especially strong for cognitive and educational traits (Abdellaoui et al., 2015), and thus it could impact the outcomes of research using the twin method on these variables. The most basic assumption of the model is that the coefficient of relatedness is 1 (i.e. $100 \%$ genetic similarity) between monozygotic twin pairs and .5 (i.e. 50\% similarity on average) between dizygotic twin pairs. Assortative mating will increase the genetic similarity between dizygotic twins but cannot increase genetic similarity between monozygotic twins because they are already $100 \%$ similar genetically. In this way, assortative mating will lead to underestimation of genetic effects and overestimation of shared environmental effects (Røysamb \& Tambs, 2016). Although evidence of assortative mating is well established particularly for cognitive and educational phenotypes, given the weak estimates of shared environmental effects evinced by the association between $g$ and achievement from middle childhood, this limitation is unlikely to have had a major impact on the research reviewed so far.

A third limitation of the twin method is the inability of classical twin models to disentangle the interplay between genotype and environment. The interplay of genes and environments happens through two main processes: gene-environment correlation (GE correlation, described earlier) and gene-by-environment interaction (GE interaction). GE interaction is observed when the effects of a person's genotype on a trait vary as a function of the environment and, vice versa, when environmental effects are more or less prominent depending on a person's genotype (Duncan \& Keller, 2011). This interaction between genes and environments can influence the variance in a trait independently from the individual prediction that genes and environments have on that trait (Manuck \& McCaffery, 2014). For example, students who have a genetic predisposition to be high achievers may thrive if they are raised in enriched environments that provide adequate stimulation. Conversely, the same students may be less likely to achieve good grades if they grow up in less optimal environments, despite their substantial genetic predisposition to be high achievers. The evidence for this GE interaction effect, where parental socioeconomic status moderates the heritability of cognitive abilities -dubbed the "Scarr-Rowe interaction", since it was first noted by Scarr (1971) and Rowe et al. (1999)- is mixed. A large 
meta-analysis suggests that it is largely culture-dependent: substantial interaction effects were observed in samples across the United States but not in European samples (Tucker-Drob \& Bates, 2016).

One additional limitation that is likely to impact not only twin studies specifically, but all cohort studies more generally is the possibility that the sample is subject to self-selection biases and therefore not representative of the larger population. Moreover, it is particularly important to consider this limitation when studying early development in twin samples since evidence suggests that twins might be at a slight disadvantage during perinatal development as compared to singletons (Martin, Boomsma, \& Machin, 1997). However, evidence from a whole population twin study across two countries found highly consistent patterns of results to those obtained from cohort studies of twins on the association between cognitive ability and academic performance (Calvin et al., 2012).

A fifth limitation of research applying the twin method is that it does not identify the specific genes involved in the observed variation and covariation between traits. However, molecular genetic studies are not subject to this limitation, and can estimate the genetic influences on traits and their covariations free from most of the assumptions and limitations reviewed above. Furthermore, very recently, studies using DNA-based methods have started addressing the role of gene-environment interplay in variation in cognitive ability and academic performance (Bates et al., 2018; Cheesman et al., 2019; Kong et al., 2018; Selzam et al., 2019). Although this special issue is mostly concerned with reviewing and evaluating evidence that has emerged from twin research, in the section that follows we provide an overview of the most recent findings on the genetics of the association between cognitive ability and academic performance stemming from studies that have applied DNA-based methods, which largely confirm the results of twin studies. We evaluate advantages and limitations of this fast-growing field of research.

\section{Moving into the molecular space: the genetics of cognitive ability and academic performance using DNA- based methods}

Early research concerned with identifying genetic variants associated with individual differences in behaviour started by focusing on examining the role of single or a small number of genetic variants, often selected on the basis of their biological or functional significance. This candidate gene approach, at odds with the substantial polygenicity observed for all behavioural traits, yielded several false positive results that lacked solid replications (Chabris et al., 2012). One of the major problems with the candidate gene approach was its reliance on small sample sizes, which yielded little power to detect associations of small effect size: the associations that were found, therefore, suffered from the "winner's curse", where they were likely to be 
inflated and due to chance. Small samples were largely due to the fact that genotyping was very expensive for the first decade of the twenty-first century. A technological advance that assessed hundreds of thousands of DNA differences (single-nucleotide polymorphisms, SNPs) enabled an atheoretical approach to identify associations across the genome, called genome-wide association (GWA). The substantial decrease in cost of GWA analyses during the past decade coincided with larger samples becoming available, and large-scale biobank studies were launched.

Genome-wide association studies of cognitive ability and academic performance

Recently, GWA studies have begun to identify SNPs associated with individual differences in cognitive ability and educational attainment (Davies et al., 2018; Lee et al., 2018; Okbay et al., 2016; Rietveld et al., 2013; Savage et al., 2018; Sniekers et al., 2017). The first major finding that has emerged from GWA studies of all complex traits is that no associations of large effect size have been discovered - the largest effects are much smaller than anyone anticipated. This means that heritability is due to many DNA differences, that is, virtually all phenotypes are highly polygenic. This finding is so common that it has been described as a "Law" of behavioural genetics: '... typical human behavioural trait is associated with very many genetic variants, each of which accounts for a very small percentage of the behavioural variability' (Chabris, Lee, Cesarini, Benjamin, \& Laibson, 2015).

GWA studies have investigated the specific genetic variants that are associated with cognitive performance (Lee et al., 2018; Sniekers et al., 2017) and educational attainment (Lee et al., 2018; Okbay et al., 2016; Rietveld et al., 2013). As the sample sizes of these investigations increase, with the latest GWA of educational attainment (EA3) including >1.1 million participants, and that of cognitive performance (IQ3) including >250,000 participants (Lee et al., 2018; Savage et al., 2018), increasingly more insight into the molecular genetic architecture of cognitive ability and academic performance has started to emerge. These continuously-increasing sample sizes have allowed for a great deal of statistical power, and the ability to uncover more and more SNPs - each of miniscule effect size- that are associated with educational attainment and cognitive performance. In fact, the latest GWA analyses identified 1,271 approximately independent loci associated with educational attainment (EA3), and 225 loci associated with cognitive performance (IQ3; Lee et al., 2018). The IQ3 results stemming from a complementary effort in partly overlapping cohorts, with a total sample size of 269,867 were highly consistent, identifying 205 mostly overlapping loci (Savage et al., 2018).

The success of a GWA study for a given trait depends on multiple factors including the genetic architecture of such trait, the sample size, and trait heterogeneity; the latter is directly related not only to the 
biology of the trait, but also to how accurately we can measure that trait in the population (Visscher et al., 2017). The GWA studies of educational attainment and cognitive performance are the most powerful genediscovery efforts in the behavioural sciences to date (Plomin \& von Stumm, 2018). In addition, these powerful GWA studies point, more generally, to the reliability of the methodology. GWA studies have been met with criticism both regarding their purpose and their discoveries (Visscher, Brown, McCarthy, \& Yang, 2012; Visscher et al., 2017). However, two recent independent efforts to uncover the genetic variants associated with cognitive performance in partly overlapping samples (Savage et al., 2018; Lee et al, 2018) have resulted in highly consistent findings. Similarly, results are highly consistent across iterations of the GWA studies of educational attainment (i.e. EA1, EA2 and EA3), and genetic correlations are substantial, although not perfect, between different cohorts (Lee et al., 2018). As noted by the authors: 'imperfect genetic correlation across cohorts will be the norm for phenotypes, such as educational attainment, that are environmentally contingent.' (Lee et al., 2018, p. 6). Therefore, the accomplishments of GWA studies of cognitive performance and educational attainment extend beyond their successful discoveries of genetic variants, to highlight the robustness of GWA discoveries.

Pleiotropic effects between cognition and education leveraging GWA discoveries

Methodological advances have made it possible to calculate genetic correlations between traits based on GWA discoveries. The most widely used method is cross-trait linkage disequilibrium (LD) score regression, which estimates genetic correlations based on GWA summary statistics unbiased by sample overlap (BulikSullivan et al., 2015). Applying LD score regression, it is therefore possible to calculate genetic correlations between educational attainment and cognitive performance, entirely from DNA, free from the majority of the assumptions that apply to family-based designs such as the twin method. A substantial genetic correlation was found between educational attainment and $g\left(r_{g}=.66\right.$; Lee et al., 2018), which is in line with estimates of genetic correlations obtained from twin studies and Genome-wide Complex Trait Analysis (GCTA; Rimfeld et al., 2015). Applying LD score regression, strong correlations have also been observed between the genetics of cognitive performance and the genetics of two additional educationally-relevant traits: highest level of mathematics class completed $\left(r_{g}=.64\right)$ and self-rated mathematics ability $\left(r_{g}=.60\right)$; in addition, these two traits shared strong genetic correlations with educational attainment ( $r g=.80$ and .51, respectively; Lee et al., 2018). Overall, these results are in line with estimates of genetic associations between cognitive and academic performance that emerged from decades of twin research and DNA-based methods like GCTA (Yang, Lee, Goddard, \& Visscher, 2011). 
Another method estimates associations directly between SNPs emerging from GWA discovery and phenotypic variation in independent samples. As noted, each significant SNP association accounts for only a very small proportion of the heritability of complex traits (Chabris et al., 2015; Manolio, 2009). However, because genetic variants combine additively to influence trait development, the genetic effects on a trait can be captured by adding up individual SNP effects across the genome (Plomin \& von Stumm, 2018). This can be achieved through creating a genome wide polygenic score (GPS). A GPS can be calculated for every individual as the sum of trait-associated alleles, weighted by the GWA study effect size for a particular trait (Dudbridge, 2013). These summary genetic scores are continuously distributed in the population; that is, some individuals carry different numbers of SNP variants associated with the trait. Consequently, a GPS constructed aggregating across SNPs associated with variation in cognitive ability or educational attainment can be considered a measure of individual-specific genetic propensity towards these traits (Plomin \& von Stumm, 2018).

Importantly, the GPS constructed from the GWA studies of cognitive ability educational attainment are not limited to predicting their target traits (Davies et al., 2018; Savage et al., 2018; Selzam et al., 2017). For example, a GPS constructed from an earlier GWA analysis of educational attainment including >290,000 participants (EA2; Okbay, Beauchamp, Fontana, Lee, Pers, Rietveld, Turley, Benjamin, et al., 2016) was found to predict variation in teacher-rated academic achievement at every stage of compulsory education (Selzam et al., 2017). Interestingly, the effect size of this DNA-based prediction increased with age, with the EA2 GPS accounting for nearly $3 \%$ of the variance in achievement at age $7,>4.5 \%$ at age 12 and $>9 \%$ of the phenotypic variance in standardized educational exam scores at age 16. The EA2 GPS also accounted for individual differences in $g$ (approximately 3.5\%; Selzam et al., 2017). Highly consistent predictions are observed when considering teacher-rated and test-based measures of academic achievement over development using the same EA2 GPS (Rimfeld, Malanchini et al., 2018). The predictive power of the GPS generated from the EA3 GWA study is even greater. In two independent samples of American adults, the EA3 GPS was found to predict $12.7 \%$ and $10.6 \%$ of the phenotypic variance in educational attainment, respectively (Lee at el., 2018). Moreover, the EA3 GPS based on educational attainment in adults predicts up to15\% of the variance in tested educational achievement at age 16 (Allegrini et al., 2019), which is the most powerful GPS prediction reported to date in the behavioural sciences (Plomin, 2018).

Multivariate approaches to genome-wide association studies

Multivariate GWA approaches have been developed to analyse GWA summary statistics from two or more traits in conjunction and to increase power by leveraging the genetic relationships among traits. One of the main examples of such multivariate methods is the Multi-Trait Analysis of GWA (MTAG; Turley et al., 2018). 
MTAG jointly analyses GWA for multiple traits (two or more), leveraging their genetic correlation to enhance statistical power thus allowing for more accurate estimation of SNP effects for each trait included in the analysis. This method, grounded in cross-trait LD score regression, can be applied to GWA summary statistics directly, without requiring individual-level genetic data (Turley et al., 2018). The application of this multivariate method has resulted in increased power for both GWA discoveries (e.g. Hill et al., 2018) and their related GPS predictions (e.g. Lee et al., 2018; Allegrini et al., 2019).

A recent study has applied MTAG to combine the IQ2 (Sniekers et al., 2017) and EA2 GWA in order to create a more powerful GWA analysis of cognitive ability. This multivariate approach led to a substantial increase in sample size and power which in turn resulted in the identification of 187 independent loci (Hill et al., 2018) relevant to cognitive ability. This constituted a substantial boost in power as compared to the individual EA2 and IQ2 GWA analyses, which identified 74 and 18 genome-wide significant independent loci, respectively. GPS calculated after applying MTAG to GWA summary statistics have also resulted in increased predictive ability. The multivariate GPS constructed from aggregating the GWA summary statistics of four cognitive and educationally-relevant traits (EA3, IQ3, highest level of mathematics class completed and selfrated mathematics ability) was found to increase the prediction of educational attainment and cognitive ability by between $2.7 \%$ and $6.9 \%$ of the variance, depending on the sample and phenotype (Lee et al., 2018).

A further multivariate GWA approach is genomic structural equation modeling (Genomic SEM; Grotzinger et al., 2019). Based on the principles of SEM widely used in twin analyses and integrated with crosstrait LD score regression (Bulik-Sullivan et al., 2015), Genomic SEM jointly analyses GWA summary statistics for multiple traits to test hypotheses about the structure of the genetic covariance between traits. By creating latent factors from GWA summary statistics, this approach can also be used to boost power for GWA discovery and polygenic prediction (Grotzinger et al., 2019). Examining the predictive power of GPS across multiple multivariate methods, a recent study found that aggregating across educationally-relevant GWA summary statistics (EA3, IQ3, income, 'age when education was completed', and 'time spent using the computer') using Genomic SEM increased prediction of academic achievement and cognitive ability (Allegrini et al., 2019). While a GPS constructed from the single EA3 GWA summary statistics accounted for a maximum of $14.8 \%$ of the variance in academic achievement and the GPS constructed from IQ3 accounted for a maximum of $6.7 \%$ in cognitive ability, aggregating across GWA summary statistics accounted for $16 \%$ of the variance in academic achievement and $11 \%$ of the variance in $g$ at age 16. Similar boosts to predictive power were obtained when the multivariate GPS was constructed using MTAG (Allegrini et al., 2019). 
A different approach that has been applied with the aim of increasing GPS prediction is the multi-GPS technique (Krapohl et al., 2017). Different from the two methods described above, this approach works at the level of the GPS scores of individuals rather than at the level GWA summary statistics. In this framework, elastic net regularization (a regularized regression method) is applied to a number of GPS to predict trait variation. While multiple linear regressions subject to problems of multicollinearity and overfitting when a large number of correlated predictors are included in the model, elastic net regression overcomes these problems by shrinking (i.e. penalizing) parameter estimates and, at the same time, performing model selection by dropping sets of non-informative predictors (Zou \& Hastie, 2005). As a consequence, the multi-GPS approach allows for the inclusion of a very large number of variables in the regression model. Applying this multi-GPS approach has resulted in increases in the GPS predictive power of academic achievement $(+1.1 \%)$ as compared to models including a single GPS, and similarly larger effect sizes were observed for other traits such socioeconomic status and body mass index (Krapohl et al., 2017).
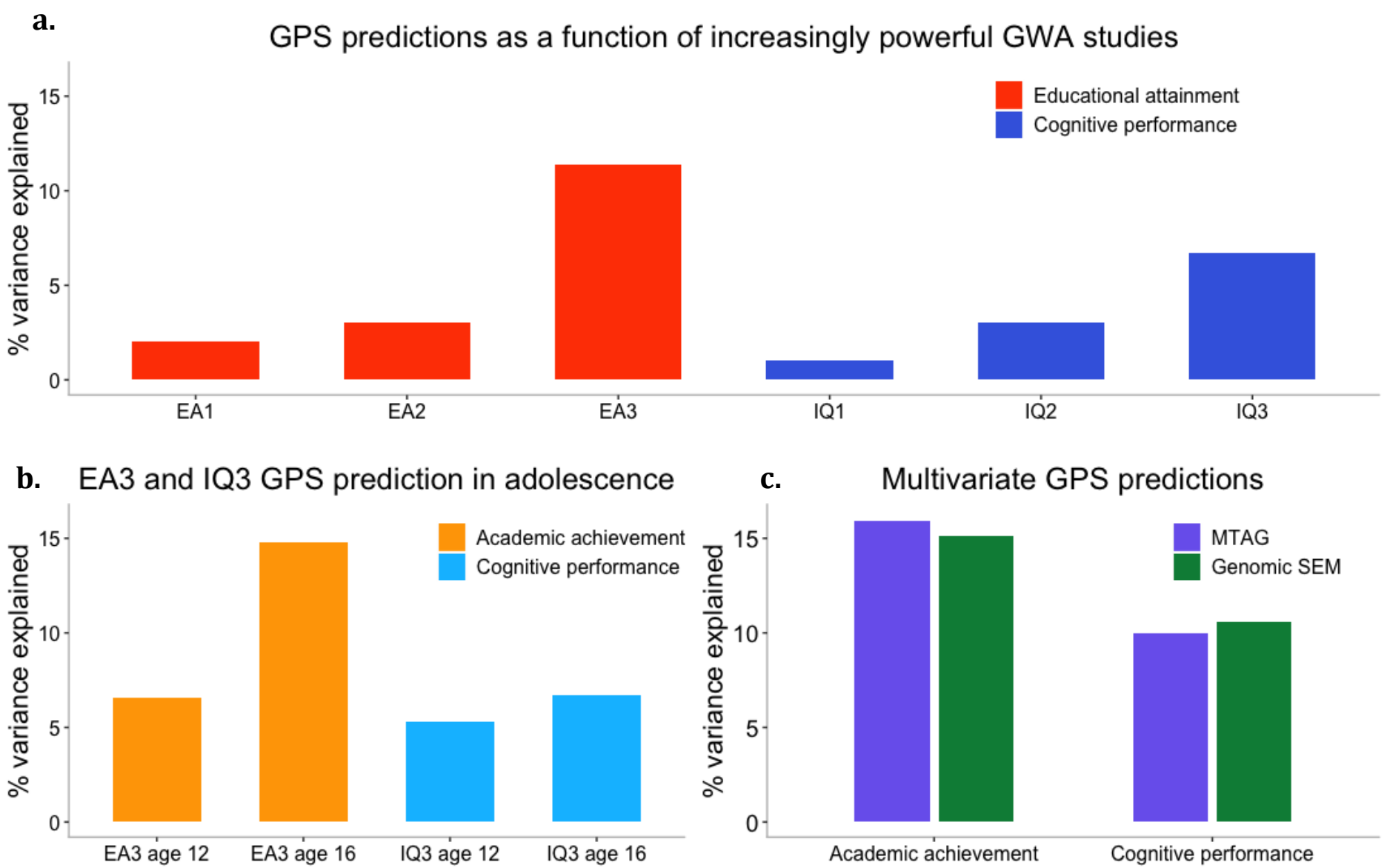

Figure 2. A few key findings on the GPS prediction of academic and cognitive performance. Panel a. illustrates how the predictive power of GPS constructed from GWAS of educational attainment (EA) and cognitive performance (IQ) increases as a function of larger sample sizes: EA1 ( 125,000; Rietveld et al., 2013), EA2 ( 290,000; Okbay et al., 2016), EA3 ( 1,100,000; Lee et al., 2018), IQ1 ( 54,000; Davies et al., 2015), IQ2 (78,000; Sniekers et al., 2017), IQ3 ( 260,000; Lee at al., 2018). Panel b. illustrates how the GPS prediction for both academic and cognitive performance increases from early to late adolescence (Allegrini et al., 2019). 
Interestingly, the GPS constructed from the GWA study of educational attainment predicts over $14 \%$ of the variance in academic achievement at age 16, measured as standardized exam scores (Allegrini et al., 2019), compared to $11.4 \%$ of the variance in educational attainment (years of education) across two adult samples (Lee et al., 2018). Panel c. shows the increase in the predictive power of GPS when adopting multivariate methods (Allegrini et al., 2019). The multivariate GPS considered in panel c. aggregated discoveries across five GWAS of traits relevant for cognition and education (EA3, IQ3, income, age when education was completed and use of computer; Allegrini et al., 2019). Different multivariate methods led to similar increases in the predictive power of GPSs.

Therefore, in line with the evidence emerging from decades of twin studies, findings from research applying the newest DNA-based methods consistently report substantial estimates of genetic influences on cognitive educational traits (Figure 2), as well as strong genetic correlations between these two broad traits.

Molecular genetic investigations into transactional processes of gene-environment interplay

But what are the implications of high heritability and strong genetic covariance between traits? What does it mean for traits to be heritable and for their covariance be explained by genetic factors?

Heritability is maximized when people are free to choose their own experiences, partly based on their genetic propensities. As such, heritability can be considered an index of equal opportunities. In line with transactional models of cognitive development, the heritability of cognitive ability (Tucker-Drob et al., 2013) and, to a lesser extent, that of academic performance (de Zeeuw et al., 2015) has been found to increase with age. This observed increase in the heritability of $g$ over development has been replicated using DNA-based methods (Trzaskowski, Yang, Visscher, \& Plomin, 2014). As children grow older, they are increasingly able to select their own experiences. Their selection of experiences is not random, instead they will be exposed to and seek out experiences that correlate with their genetic propensity, resulting in increased heritability estimates. Clever designs applying DNA-based methods have started providing concrete evidence for the effects of GE correlation on heritability estimates and GPS predictions.

One such design leverages genetic trios of mother, father, and offspring to partition the variance in the parental genotype into two parts: the genetic variants that are transmitted to the offspring and the genetic variants that are not transmitted (Bates et al., 2018; Kong et al., 2018). This design allows to examine the effects of 'genetic nurture', or the 'nature of nurture' (Plomin \& Bergeman, 1991), on variation in a trait. Genetic nurture tests whether non-inherited genetic variants contribute to variation in phenotypes through their impact on parents and siblings, thus providing evidence of genetic effects acting through environmental pathways (Koellinger \& Harden, 2018). Applying this method, a recent study found that the GPS constructed for the nontransmitted genetic variants predicted variation in educational attainment in offspring, with an effect size of approximately one third that of the GPS calculated for the transmitted genetic variants (Kong et al., 2018). This 
provides support for genetic effects influencing offspring's characteristics through their correlations with the environment (passive GE correlation). A further study using the same logic found that, in a different sample, the parental educational attainment GPS correlated with the socio-economic environment, which in turn was related to offspring's educational attainment (Bates et al., 2018). The genetic nurture design is conceptually similar to an adoption design, as it allows to separate the effects of genotype and family rearing environment. As previously discussed, the inability to do so is one of the main limitations that apply to twin studies.

Another ingenious and conceptually related design allows to disentangle the effects of genetic and environmental factors on GPS without requiring intergenerational data. This method compares the GPS prediction in adoptees and non-adoptees, based on the assumption that adoptees, by virtue of growing up with their genetically unrelated adoptive parents, are exposed to rearing environments that are less correlated with their genotypes (Cheesman et al., 2019). Applying this design in the UK Biobank sample, the study found that GPS were twice as predictive of educational attainment in non-adoptees as compared to adoptees. This is yet another line of evidence for GE correlation processes operating on educational success. In addition, when considering the bottom $10 \%$ of the education GPS in both adoptees and non-adoptees, adoptees showed greater educational attainment than non-adoptees, pointing to the potentially protective factors of being adopted in education-conducive environments (Cheesman et al., 2019).

A further conceptually related design leverages differences in GPS predictions between siblings growing up in the same family to separate genetic and environmental pathways that contribute to the GPS predictive power (Selzam et al., 2019). Siblings, like dizygotic twins, share on average $50 \%$ of the genes that differ between individuals and inherit their genotype from their parents in at random. At the same time, by virtue of growing up in the same family they are exposed to similar rearing environments. As a consequence, an association between the difference in GPS between pairs of siblings and their differences in observed trait variation can be interpreted as a causal effect of the genotype on the observed phenotype, which is also free from the confounding effects of assortative mating and population stratification. Applying this method to investigating the effects of GE correlation on cognitive ability and education, a study found that GPS predictions for academic achievement and $g$ were much greater at the between-family level than at the withinfamily level $(\sim 60 \%)$. Interestingly, the majority of this difference in prediction observed between and within families was found to be accounted for by family socio-economic status. These results provide a strong line of evidence for the importance of socioeconomic differences between families as a mechanism through which passive GE correlation is operationalized (Selzam et al., 2019). 
Heritability is not only maximized when individuals are exposed to, or free to choose, experiences that correlate with their genetic propensities at the personal level, but also major changes at the societal level may result in amplified heritability. In line with this proposition, one study found that the heritability of educational attainment in Estonia post-Soviet era, a time characterized by an increase in equal opportunities and meritocracy, was substantially higher than the heritability during the Soviet era (Rimfeld et al., 2018).

Therefore, genetic effects were found to vary as a function of social policies and of major shifts in societies, which is consistent with GE interaction processes. Providing additional support, the EA2 GPS was approximately twice as predictive of educational attainment in the post-Soviet era (Rimfeld et al., 2018). These results are in line with those of a meta-analysis testing GE interaction effects on the heritability of $g$ applying twin design. As previously discussed, evidence for GE interaction was found only in the United States, and to be potentially explained by societal differences between the United States and Europe, for example educational quality, access to healthcare, welfare and education and social mobility (Tucker-Drob \& Bates, 2016).

\section{Key limitations of DNA-based methods}

Several limitations should be considered when evaluating the findings stemming from molecular genetic research on cognitive and educational traits. The most striking limitation to date is the fact that DNA-based results are mostly based on samples of European ancestry. This limits the extension of genetic findings to the entire population (Martin et al., 2019; Popejoy \& Fullerton, 2016). Although GWA studies in populations of non-European ancestry are beginning to emerge (Emmanuel \& von Schantz, 2018) and genotyping companies are providing increasingly powerful tools for genotyping on a global scale, this remains to date a major limitation of DNA-based methods.

A second major limitation of DNA-based methods is that the genetic variants that have emerged from the most recent and powerful GWAS, explain only a small portion of the heritability of traits (narrow sense or chip heritability) as compared to twin heritability estimates (broad sense heritability). This is particularly the case for psychological and behavioural traits for which only between one to two-thirds of the twin heritability is accounted for by common genetic variants (Visscher et al., 2012). This gap in the heritability estimated from classical twin design and DNA-based methods is known as missing heritability (Maher, 2008). Several processes have been proposed to account for this missing heritability gap, including the possibility that the stringent cut-off that is applied to each SNP in GWA analyses may conceal the significant contribution of SNPs of modest effects (Manolio, 2009). A second proposition is that the current inability of GWAS to tag interactive effects between genes (epistatic effect), and between genes and environments (GE interaction) may result in the observed missing heritability gap (Aschard et al., 2012). However, as previously discussed, solid evidence of 
interaction effects is currently lacking in the behavioural and psychological literature and seems to include processes that are highly culture-specific. A third proposition is that rare variants that are not tagged by SNP arrays commonly used in GWA play a substantial role in trait variation. This hypothesis has recently been tested using whole genome sequencing data in a sample of >20,000 for two anthropometric traits: height and bodymass index (Wainschtein et al., 2019). The study found that including rare variants, particularly those in low LD, in the models recovered the majority of the heritability derived from twin studies (Wainschtein et al., 2019). However, whether similar processes apply to complex psychological and behavioural traits, including cognitive ability and educational achievement remains speculative. Finally, it has also been proposed that the twin-based heritability estimates might be inflated (Young, 2019).

Several other, more technical, limitations apply to GWA and the DNA-based methods that derive from GWA discoveries. It is beyond the scope of the current review to discuss all these at length, but an in-depth discussion of the benefits and limitations of the GWA design is available (Tam et al., 2019). In light of the limitations that currently apply to both DNA-based methods and the limitations of the classical twin design, applying multiple methodologies in conjunction would result in increasingly robust findings (Lawlor, Tilling, \& Davey Smith, 2016). Convergence between twin and DNA-based findings is beginning to emerge. For example, DNA-based findings provide some support for two developmental findings for $g$ from twin research. Twin research finds strong genetic stability for $g$ despite increasing heritability. A DNA-based study showed similar results, with a genetic correlation of .73 from age 7 to age 12 and heritability increasing from .26 at age 7 to .45 at age 12 (Trzaskowski et al, 2014). Similarly, DNA-based research has provided support for the finding of substantial genetic correlation between $g$ and academic performance, with DNA-based genetic correlations between $g$ and language, reading, and mathematics found to exceed .70 (Trzaskowski et al., 2013).'

Triangulating across multiple genetically informative methodologies is also likely to provide increasingly actionable knowledge about the biological and environmental processes that shape the development of cognitive ability and educational achievement. Novel methods have been developed to combine classical behavioural genetic methodologies with DNA-based methods. A recent example is a new technique that allows for the integration of GPS in classical twin models to estimate the effects of GE correlation (Dolan, Huijskens, Minică, Neale, \& Boomsma, 2019).

Regardless of the limitations that characterize each method and of the desirable push towards triangulating across multiple methodologies, genetic research has provided compelling evidence that has resulted in greatly advancing our knowledge and understanding of the association between cognitive ability and learning. Through rigorous genetic research that has applied both twin and DNA methods scientists have 
reached a much greater understanding of the genetic and environmental processes that shape cognitive and educational traits during development, from their stability to their molecular basis. Among the most noteworthy findings emerging from behavioural genetic research are the notions that cognitive ability and academic performance share a strong association throughout the lifespan. This increases sharply over childhood, and from mid-childhood onwards is mostly accounted for by genetic influences. Nevertheless, the phenotypic and the genetic correlation between cognitive ability and academic performance are far from unity. Although it may be intuitive to speculate that the strong stability and heritability of academic performance is driven by $g$, genetic research has shown that the stability and genetic effects on academic performance remain substantial even after accounting for $g$. This suggests that several other educationally relevant characteristics contribute to the genetic variation in academic performance. It is fundamental to acknowledge these 'noncognitive' processes and to position them within a genetically oriented model of cognitive ability and learning. Consequently, the section that follows provides a brief overview of genetically informative research that has examined variation in such educationally relevant noncognitive characteristics.

\section{The genetics of education extends beyond academic performance.}

Although the notion that skills beyond cognitive ability are important in promoting learning has been embraced by cognitive scientists for over a century (e.g. Binet \& Simon, 1916; Wechsler, 1943), the interest of behavioural genetics in noncognitive skills has emerged only recently. In fact, as compared to cognitive ability and academic performance, a significantly smaller body of genetically informative research has examined educationally relevant noncognitive characteristics. A first limitation that has hindered progress in the systematic investigation of noncognitive skills is their negative definition: they are not defined by what they are, rather by what they are not: they are not cognitive skills. A recent surge in interest in the role of noncognitive characteristics across the social sciences (Heckman, Stixrud, \& Urzua, 2006; West et al., 2016), has led to efforts in refining noncognitive traits. When considering educationally-relevant noncognitive skills, researchers have identified five key domains that contribute to educational success: personality traits, motivational factors, self-regulation, student's approaches to learning, and psychosocial influences (Richardson, Abraham, \& Bond, 2012). These domains are conceptually overlapping, yet distinguishable, and it is therefore fundamental to consider both their specific and collective role in promoting educational success.

All these different noncognitive processes have been found to relate to academic performance to varying degrees. While $g$ remains the best predictor of academic performance, accounting for between one quarter and one third of its variance, research has shown that noncognitive skills predict academic performance beyond $g$. In a sample of 16-year-olds from the United Kingdom, self-efficacy and personality, in addition to other constructs 
such as wellbeing, behavioural problems, health, and perceived home and school environments, collectively accounted for a comparable proportion of variance in academic performance as $g$ (Krapohl et al., 2014). In addition, measures of personality, self-regulation and motivation, are related to variation in academic performance beyond measures of cognitive ability (e.g. Tangney, Baumeister, \& Boone, 2004; Diamond, 2013; Muenks, Wigfield, Yang, \& O’Neal, 2017; Tangney et al., 2004; Garon-Carrier et al., 2016; Guay, Ratelle, Roy, \& Litalien, 2010; E. M. Tucker-Drob \& Harden, 2012, 2014; Chamorro-Premuzic, Harlaar, Greven, \& Plomin, 2010; Tucker-Drob \& Briley, 2012).

Twin studies of the association between noncognitive processes, general cognitive ability and academic performance

Behavioural genetic studies have examined the genetic and environmental underpinnings of personality traits, finding moderate genetic influences across personality characteristics, little to no contribution of shared environment, and an increasingly important role of nonshared environmental influences on personality traits over the lifespan (see Briley \& Tucker-Drob, 2014, 2017 for comprehensive reviews of the available evidence). On the contrary, research that has investigated the genetic and environmental origins of self-regulatory processes, measured through executive functions, has found support for a major contribution of genetic factors (Engelhardt, Briley, Mann, Harden, \& Tucker-Drob, 2015; Laura E Engelhardt et al., 2016; Friedman \& Miyake, 2017). Indeed, the heritability of executive functions was found to approach unity (Engelhardt et al., 2015).

Less genetically informative research has been devoted to investigating the genetic and environmental underpinnings of motivational factors and students' approaches to learning. The available evidence suggest that motivational processes, such as self-efficacy and interest, are moderately heritable and that nonshared environmental factors contribute substantially to individual differences in motivation during childhood and adolescence across several countries (Kovas et al., 2015; Tucker-Drob et al., 2016). Genetic and environmental effects on students' approaches to learning, measured as goal-orientation, have been found to shift with age, with environmental influences being the primary source of variation during childhood and a gradual increase in genetic influence during adolescence and adulthood (Zheng et al., 2019). Combining evidence from phenotypic and genetic research points to how noncognitive skills represent a very broad, eclectic and complex phenotype.

In an attempt to dissect the complexity of the noncognitive phenotype, genetically informative studies have examined associations between a few 'key' educationally relevant noncognitive variables and academic performance, most notably, grit (Duckworth, Peterson, Matthews, \& Kelly, 2007) and motivation. Grit, a 
psychological construct that describes perseverance and passion to achieve long-term goals (Duckworth et al., 2007), is closely related to the personality dimensions of conscientiousness (Rimfeld, Kovas, Dale, \& Plomin, 2016) and self-control (Duckworth \& Gross, 2014), sharing strong phenotypic and genetic correlations with them (Malanchini et al., 2018). In sample of 16-year-olds, the modest correlation between grit and academic achievement was found to be largely due to shared genetic variance, and to a lower extent to nonshared environmental variance (Rimfeld, et al., 2016). These genetic and environmental effects, however, could almost entirely be accounted for by conscientiousness, questioning the role off grit as a specific key component of academic success (Credé, Tynan, \& Harms, 2017; Rimfeld, et al., 2016).

The moderate links between individual differences in academic achievement and academic motivation (Gottschling, Spengler, Spinath, \& Spinath, 2012) and other more targeted motivational constructs, such as selfperceived ability (Greven et al., 2009), were also found to correlate primarily for genetic reasons across two samples of primary and secondary school students cross-culturally (Gottschling, Spengler, Spinath, \& Spinath, 2012; Greven, Harlaar, Kovas, Chamorro-Premuzic, \& Plomin, 2009; Luo et al., 2010). Nonshared environmental factors provided a weaker contribution to the association, while shared environmental factors were not implicated in the association between motivation and academic achievement. While noncognitive traits vary substantially in their aetiology, when considering the concurrent association between specific educationally relevant noncognitive characteristics and academic performance, genetic factors seem to constitute the major systematic source of covariation.

Reciprocal models of the association between noncognitive factors and academic performance propose that their association is subject to a process of mutual influence that results in their relation being maintained over development (Morgan \& Fuchs, 2007). Longitudinal studies have supported these reciprocal models, finding longitudinal developmental links between noncognitive characteristics and achievement (e.g. ChamorroPremuzic et al., 2010; Guay et al., 2003; Marsh \& Martin, 2011; Muijs, 1997). A handful of studies have examined the origins of such longitudinal links applying genetically informative designs. For example, the longitudinal relations between self-perceived ability and academic performance between the ages of 9 and 12 was found to be characterized by reciprocal links, mediated largely through genetic pathways (Luo et al., 2010).

Two further studies in the same sample have explored associations between multiple aspects of motivated behaviour (self-perceived ability and interest) and teacher-rated achievement in the context of mathematics learning (Luo, Kovas, Haworth, \& Plomin, 2011) and reading ability (Malanchini et al., 2017). In the context of mathematics achievement, one study found that while the link from earlier achievement (age 9) to subsequent motivation (age 12) was mostly attributable to genetic factors, the link from early motivation to 
subsequent achievement was mediated through both genetic and child-specific environmental pathways (Luo et al., 2011). Results of the investigation into the association between motivation for reading and reading ability provided highly consistent results. Applying for the first time a genetically sensitive full cross-lagged panel analysis (ACE cross-lagged; Malanchini et al., 2017), the study found that, while the path from early reading to later variation in motivation was almost entirely genetic in origin, the path from early motivation to subsequent reading comprehension was explained by both genetic and environmental factors (Malanchini et al., 2017). Interestingly, both studies found that longitudinal associations remained significant and similar in their aetiology even when statistically controlling for $g$ (Malanchini et al., 2017; Luo \& Kovas, 2011).

While some genetically informative research has examined the genetic and environmental underpinnings of the association between targeted noncognitive characteristics and academic performance, a handful of investigations have examined the collective contribution of multiple aspects of the noncognitive umbrella to variation in academic achievement. In one of the most comprehensive investigations of educationally-relevant noncognitive skills to date, Tucker-Drob et al. (2016) found that two second-order latent factors that captured covariation among multiple measures of childhood character (motivation, attitudes and personality processes) were moderately heritable and shared genetic links with academic achievement, even after controlling for fluid intelligence (Tucker-Drob et al., 2016).

An even more comprehensive investigation conducted in a partly overlapping sample of twins examined how multiple aspects of self-regulation, personality and motivation contributed, individually and collectively, to variation in reading and mathematics ability (Malanchini et al., 2018). The investigation found that beyond cognitive ability, self-regulation contributed substantially to variation in reading and mathematics, and that these pathways were largely genetic in origin. In addition, while aspects of personality, motivation and attitudes related to conscientiousness (e.g. effortful persistence, self-discipline and diligence) did not account for further variation in academic achievement, aspects of personality, motivation and attitudes related to openness (e.g. curiosity, interest and self-efficacy) further contributed to academic performance, particularly in reading. These links between facets of openness and achievement was largely mediated by genetic effects. Remarkably, when examined in conjunction, measures of cognitive abilities, self-regulation, personality, motivation and attitudes towards learning accounted for the entirety of the genetic variance in reading and mathematics in this child sample (Malanchini et al., 2018). No study to date has tested how these multiple noncognitive, cognitive and educational processes interact and influence each other over development applying formal longitudinal methods. Overall results are in line with the description of intellectual curiosity as the 'third pillar of academic performance' beyond intelligence and conscientiousness (von Stumm, Hell, \& Chamorro-Premuzic, 2011). 
Even fewer studies have examined the genetic architecture of selected noncognitive skills and of their association with academic performance and cognitive ability using DNA-based methods. One of the earlier studies to link variation in the GPS constructed from the first GWA study of educational attainment (EA1; Rietveld, 2013) to noncognitive characteristics, found that children with higher educational attainment GPS tended to show higher level of self-control (Belsky et al., 2016). In addition, the same study found that selfcontrol and interpersonal skills mediated the prediction form the educational attainment PGS to positive life outcomes in adulthood including higher educational and professional success (Belsky et al., 2016). A further study has examined how the educational attainment GPS could predict variation in the big five factors of personality (Costa \& McCrae, 1992) and a broad motivation composite. The study found that the EA3 GPS was related to three aspects of personality (conscientiousness, agreeableness and openness), accounting for between $0.6 \%$ and $2 \%$ of their variance, and to academic motivation, accounting for nearly $3 \%$ of its variance. Furthermore, the study examined whether the EA3 GPS could account for the association between each noncognitive skill and academic achievement at age 16, finding that it explained between $8 \%$ and $16 \%$ of the correlations between them (Smith-Woolley, Selzam, \& Plomin, 2019).

While these two studies applied GWA discoveries in the field of educational attainment to the investigation of noncognitive skills, one recent study has looked into the heritability and covariation between multiple noncognitive skills using DNA-based methods. Estimating univariate heritability and pairwise genetic correlations in large samples of unrelated individuals using GCTA (Yang et al., 2011), the investigation found that across multiple measures of noncognitive skills (including personality, self-regulation, and motivation), estimates of heritability and genetic correlations between measures were weak (Morris, Smith, Berg, \& Davies, 2018). In addition, all noncognitive measures shared weak genetic associations with educational or professional success. These results, inconsistent with the moderate heritability estimates and correlations emerging from twin research, could point to several weaknesses and limitations that currently exist in the quest to identify the genetic architecture of noncognitive skills.

The first challenge in pushing the identification of the genetic architecture of noncognitive skills forward is measuring them reliably, an issue that is rooted in their broad all-encompassing definition, as well as in the fact that measurement relies nearly exclusively on self-reports. The fact the noncognitive phenotype is an agglomerate of many different skills and characteristics that correlate to varying degrees poses a major challenge: the availability of a comprehensive enough battery of tests that would enable extraction of reliable components (e.g. Tucker-Drob et al., 2016). Reliable composite measures that reflect commonalities across 
noncognitive skills would likely result in advancing our understanding of the molecular genetic architecture of noncognitive skills. However, administering long batteries of noncognitive tests to the very large samples needed for GWA discovery is likely to prove challenging. One potential way forward could be creating short, easy to administer, online batteries that specifically target characteristics that are common across noncognitive skills in order to quickly extract few reliable measures. A second possibility would be to leverage recent advances in multivariate GWA methods, for example Genomic SEM (Grotzinger et al., 2019), to create latent GWA analyses of noncognitive skills (Demange et al., in preparation).

The difficulty in reliably getting to the molecular basis of noncognitive skills points to a broader issue: the importance of phenotypes in genetic discoveries. Although this fundamental issue is beyond the scope of the current review, measurement heterogeneity is likely to have a major impact in GWA discoveries, particularly when working with complex behaviours and conditions such as human motivation or psychopathologies (Chabris et al., 2013). Methods such as Genomic SEM that can parse generality from specificity are likely to contribute importantly to the quest to dissect the heterogeneity of phenotypes. Alternative toolkits are being developed, for example, to dissect the genetic heterogeneity in major depression (McIntosh, Sullivan, \& Lewis, 2019).

\section{Towards a comprehensive, evidence-based model of learning: cognitive ability, academic performance and noncognitive skills in the context of genotypes and environments}

Although noncognitive skills have been the subject of much less behavioural genetic research, recent studies have begun to clarify how genetic and environmental factors contribute to individual differences in this heterogeneous phenotype and, importantly, the genetic and environmental underpinnings for its association with academic performance and cognitive ability. Indeed, considering both cognitive and noncognitive skills and their biological and environmental underpinnings is fundamental if the goal is to move towards a comprehensive, evidence-based model of education.

Extant studies point to the great benefits that come from considering both cognitive and noncognitive skills in conjunction in order to predict life outcomes such as educational and professional success, morbidity and mortality. One study conducted in a large longitudinal sample has shown that the strength of the prediction of adult outcomes from childhood risk increased significantly when cognitive and noncognitive characteristics (childhood IQ and childhood self-control) were considered jointly rather than in isolation (Caspi et al., 2016). In line with Pareto's principle, the study showed that around $20 \%$ of the population was found to account for around $80 \%$ of adult economically burdensome outcomes, from tobacco smoking to criminal convictions and 
hospitalizations. Childhood cognitive and noncognitive skills, together with growing up in socioeconomic disadvantage, predicted these economically burdensome outcomes with great accuracy (Area Under the Curve of .87; Caspi et al. 2016). Such evidence not only highlights the importance of considering cognitive and noncognitive skills in conjunction for both prediction and intervention purposes, but also of considering environmental risk factors together with genetic predispositions.

In addition to being partly rooted in genetic variation, the association between $g$, educational performance and life outcomes is also shaped by the socioecological context (Engelhardt, Church, Harden, \& Tucker-Drob, 2018) and its related behaviours, also described in the literature as the behavioural constellation of deprivation (Pepper \& Nettle, 2017). It has been proposed that the reduced wealth and influence that are generally associated with socioeconomic deprivation are likely to result in an increased inability to affect one's future outcomes, from educational attainment to illness. One of the psychological processes proposed to be key for these observed links between deprivation and unfavourable life outcomes is a lack of experienced and perceived personal control, since 'Limited personal control may include a restricted ability to ensure that returns on investments made in the present, for payoffs in the future, will be received' (Pepper \& Nettle 2017, p.3). As a consequence, motivational processes based on different expectations of the future may contribute to, or exacerbate, the discrepancy in life outcomes observed between individuals belonging to different socioeconomic brackets.

As previously discussed, social processes such as those included in the behavioural constellation of deprivation (Pepper \& Nettle, 2017) and genetic processes likely act in concert to give rise to variation in traits that are ultimately linked to differential life outcomes. Transactional models, rooted in GE correlation, provide a suitable framework for pushing our conceptualization of education towards embracing the important discoveries that stem from behavioral genetic research. As discussed earlier, transactional models propose that genotypeenvironment correlation promotes differences in environmental experiences, which in turn impact cognitive development and academic achievement (Briley \& Tucker-Drob, 2013). Some of the genetically-influenced environmental experiences that have been associated with being exposed to, selecting, and evoking educationally relevant environments are noncognitive skills such as attitudes and motivation (Tucker-Drob \& Harden, 2012). In line with this framework, students would select, evoke and experience learning environments, partly depending on their differences in cognitive and noncognitive characteristics, which are themselves partly genetically influenced.

Six main criteria have been proposed as necessary in order to find empirical support for the transactional model of the association between noncognitive traits and academic achievement. First, a correlation between the 
noncognitive trait and achievement is necessary, although not sufficient. Second, their correlation should be significant beyond their association with general cognitive ability. Third, the model requires noncognitive factors to be moderately heritable. Fourth, there should be a degree of genetic correlation between the noncognitive trait and academic achievement. Fifth, the direction of causation, evaluated through longitudinal panel analyses, should be significant from the noncognitive trait to achievement. And sixth, environmental experiences should mediate the association between noncognitive traits and achievement though a genetic pathway (Tucker-Drob \& Harden, 2017). The evidence reviewed so far supports the first five criteria and consequently the possibility that transactional processes operate not only for cognitive ability and achievement, but also for noncognitive characteristics.'

Future research identifying the specific environmental experiences that mediate these genetic links will prove essential for the development of evidence-based interventions. As Petrill and Wilkerson state in an earlier review on the genetics of the association between intelligence and achievement: 'Far from passively receiving an educational program, children may be actively seeking out and receiving enriched environments based, in part, on genetic influences. Not only should our research begin to identify these multiple influences on intelligence and achievement, but our educational practices should also be more sensitive to these sources of individual differences' (Petrill \& Wilkerson, 2000).

Evidence stemming from behavioural genetic research on cognitive and educational traits has provided valuable insights into why such stark individual differences are observed at every stage over the lifespan. This wealth of knowledge should also guide how we evaluate educational interventions (Sokolowski \& Ansari, 2018). It is customary to evaluate educational interventions on the basis of two chief goals: first, interventions should provide a shift in the distribution of ability, which would indicate that every child benefit from the intervention; second, interventions should aim to reduce the gap between high and low achievers. As argued by Sokolowski and Ansari, while the first goal is feasible and highly desirable, as interventions should provide children with the opportunity to reach their full potential, given what we know from genetic research, the second goal may not be a reliable index of successful interventions as it is traditionally assumed. In fact, even if environmental experiences are equalized, remarkable individual differences will still be observed, as these are partly rooted in genetic differences between students (Sokolowski \& Ansari, 2018). While equal opportunities of access to educational resources are highly desirable, these are unlikely to result in equivalent abilities or achievement between students, which instead are the product of a complex interplay between genetic and environmental processes.

Implications for the present and future of educational practice. 
We propose that the evidence stemming from decades of behavioural genetic research into cognitive ability and education is not only valuable in informing the evaluation of educational interventions but could also be integrated into the development and implementation of successful personalized education. Educational curricula would benefit from embracing individual differences between students, which are partly due to genetic differences between them (Asbury \& Plomin, 2013). Cutting-edge tools, like GPS, that are able to leverage information on genetic differences between individuals to provide a probabilistic index of dispositions and capabilities, could be integrated into the development of early interventions, particularly as an additional tool to inform early screening.

Taking the example of reading disability, the capability to predict whether a child is at risk of struggling with reading before the start of schooling would provide parents and educators with an opportunity to develop targeted prevention and interventions strategies that may result in better outcomes (Plomin, 2019). This can be beneficial for several reasons. First, early interventions have better prognoses. They are consistently found to lead to greater improvements, particularly if sustained over development (Sokolowski \& Ansari, 2018). Second, at the moment, children are screened for reading disabilities only when they start to display behavioural difficulties. This is not only highly inefficient, but it could hinder children's learning potential by promoting negative experiences which would in turn impact achievement. In line with findings from longitudinal research (e.g. Malanchini et al., 2017), children who struggle with reading are more likely to develop negative attitudes towards reading and to avoid reading. This is likely to generate a downward spiral. Third, children who struggle with achievement are more likely to show symptoms of anxiety related to learning (Ma, Xu, \& Xu, 2004; Wang, Shakeshaft, Schofield, \& Malanchini, 2018), this is not only detrimental for academic performance, but, most importantly, it may have profound, long-lasting consequence for students' wellbeing and mental health.

The ability in the future to predict educational difficulties early in development, even before they are manifested, is likely to be fundamental in ameliorating educational outcomes and experiences for all students, but particularly for those at risk of struggling with learning difficulties. Using genetic information as an additional early screening tool may therefore prevent the spiralling negative consequences associated with delayed diagnoses. The same principle can be applied to several other aspects of learning, including noncognitive skills.

There are several caveats and limitations that apply to the possibility of integrating genetic prediction into personalized approaches to learning and interventions. First and foremost, GPS prediction is far from perfect, accounting for at best $\sim 15 \%$ of the variation in academic achievement at the end of compulsory 
education and substantially less at earlier ages (Allegrini et al., 2019; Selzam et al., 2017; Rimfeld, Malanchini et al., 2018). Of course, no predictions in the behavioural sciences are perfect, which means that predictions at the individual level have very wide confidence intervals. Consequently, predicting variation in academic performance, particularly in the early years, from DNA alone, is unlikely to lead to accurate results for an individual, although at the extremes of the GPS distribution, substantial average differences can be predicted. For example, for the lowest decile of EA3, about $25 \%$ go to university, whereas about $75 \%$ from the highest decile go to university (von Stumm et al., 2019).

Second, genetic effects are likely to conceal a combination of 'true' genetic variation and environmental effects, due to, as previously discussed, gene-environment interplay. Most notably, recent studies have shown that non-inherited genetic variants can contribute to variation in phenotypes through their impact on parents and other relatives, therefore, providing evidence for genetic effects operating indirectly through the environment, a process termed genetic nurture (Kong et al., 201; Bates et al., 2018). Third, transactional processes rooted in evocative and active gene-environment correlation are likely to account for a substantial portion of the genetic prediction of academic performance (Tucker-Drob \& Harden, 2017; Cheesman et al., 2019; Selzam et al., 2019). A more in-depth discussion of these issues is available (Briley \& Tucker-Drob, 2019). In light of this interplay between genes and environments, identifying the specific environmental and biological processes that lead from genetic predisposition to observed variation in cognition and education remains one of the major challenges for future research. This will likely lead to advances in personalized, more effective approaches to learning and early interventions.

\section{Conclusions}

Genetic research into cognitive ability and education has provided crucial insights into why children differ so widely in their abilities, attitudes and appetites for learning. As our knowledge continues growing and new methods and tools are developed, the information that emerges from genetic research becomes increasingly tangible, translational and actionable, for example by informing the way we evaluate and develop educational interventions. Decades of twin studies and, more recently DNA-based discoveries, point to the importance of genetic variation in cognitive ability and education and in their close association. These genetic influences, however, do not just happen in isolation, rather they are shaped by their interplay with the environment. Recent advances in molecular genetics provide increasingly comprehensive and accessible tools that have been applied to the investigation of these complex processes of correlation and interaction between genes and environments. 
While our knowledge of the genetic and environmental underpinnings of the association between cognitive ability and education has grown exponentially in recent years, several gaps in our knowledge still exist. First and foremost, longitudinal genetically informative research into the association between cognitive ability and education is still lacking. This is particularly important as genetic and environmental influences on cognitive ability and educationally relevant processes are not static, rather they evolve and shift during development (e.g. Zheng et al., 2019; Briley \& Tucker-Drob, 2017). In addition, we need to develop novel ways of assessing cognitive and educational traits briefly and reliably in large samples to result in breakthroughs in genetic discoveries. Lastly, research investigating how biologically relevant models of cognitive ability and educational traits can be integrated in educational practices, for example, by running randomized control trials of intervention programs, is still lacking. We look forward to the next decades of behavioural genetic research into cognitive ability and education, as we continue learning about learning.

\section{Acknowledgements}

We gratefully acknowledge the ongoing contribution of the participants in the Twins Early Development Study (TEDS) and their families. TEDS is supported by a program grant to R.P. from the UK Medical Research Council (MR/M021475/1 and previously G0901245), with additional support from the US National Institutes of Health (AG046938). The research leading to these results has also received funding from the European Research Council under the European Union's Seventh Framework Programme (FP7/2007-2013)/ grant agreement n. 602768. R.P. is supported by a Medical Research Council Professorship award (G19/2). M.M.'s work is partly supported by the David Wechsler Early Career grant for innovative work in cognition.

\section{References}

Abdellaoui, A., Hottenga, J. J., Willemsen, G., Bartels, M., Van Beijsterveldt, T., Ehli, E. A., ... Boomsma, D. I. (2015). Educational attainment influences levels of homozygosity through migration and assortative mating. PLoS ONE, 10(3), 1-14. https://doi.org/10.1371/journal.pone.0118935

Allegrini, A. G., Selzam, S., Rimfeld, K., von Stumm, S., Pingault, J. B., \& Plomin, R. (2019). Genomic prediction of cognitive traits in childhood and adolescence. Molecular Psychiatry, 000, 819-827. https://doi.org/10.1038/s41380-019-0394-4

Alloway, T. P., \& Alloway, R. G. (2010). Investigating the predictive roles of working memory and IQ in academic attainment. Journal of Experimental Child Psychology, 106(1), 20-29. https://doi.org/10.1016/j.jecp.2009.11.003

Arden, R., Trzaskowski, M., Garfield, V., \& Plomin, R. (2014). Genes Influence Young Children's Human 
Figure Drawings and Their Association With Intelligence a Decade Later. Psychological Science, 25(10), 1843-1850. https://doi.org/10.1177/0956797614540686

Asbury, K., \& Plomin, R. (2013). G is for genes: The impact of genetics on education and achievement (Vol. 24). John Wiley \& Sons.

Aschard, H., Chen, J., Cornelis, M. C., Chibnik, L. B., Karlson, E. W., \& Kraft, P. (2012). Inclusion of genegene and gene-environment interactions unlikely to dramatically improve risk prediction for complex diseases. American Journal of Human Genetics, 90(6), 962-972. https://doi.org/10.1016/j.ajhg.2012.04.017

Ask, H., Idstad, M., Engdahl, B., \& Tambs, K. (2013). Non-random mating and convergence over time for mental health, life satisfaction, and personality: The Nord-Trøndelag health study. Behavior Genetics, 43(2), 108-119. https://doi.org/10.1007/s10519-012-9578-2

Bailey, D. H., \& Littlefield, A. K. (2017). Does Reading Cause Later Intelligence? Accounting for Stability in Models of Change. Child Development, 88(6), 1913-1921. https://doi.org/10.1111/cdev.12669

Bartels, M., Rietveld, M. J. H., Van Baal, G. C. M. ., \& Boomsma, D. I. (2002). Genetic and Environmental Influences on the Development of Intelligence. Behavior Genetics, 32(4), 237-249. https://doi.org/10.1093/oxfordjournals.bmb.a070814

Bartels, Meike, Rietveld, M. J. H., Van Baal, G. C. M., \& Boomsma, D. I. (2002). Heritability of educational achievement in 12-year-olds and the overlap with cognitive ability. Twin Research, 5(6), 544-553. https://doi.org/10.1375/136905202762342017

Bates, T. C., Maher, B. S., Medland, S. E., McAloney, K., Wright, M. J., Hansell, N. K., ... Gillespie, N. A. (2018). The Nature of Nurture: Using a Virtual-Parent Design to Test Parenting Effects on Children's Educational Attainment in Genotyped Families. Twin Research and Human Genetics, 21(2), $73-83$. https://doi.org/10.1017/thg.2018.11

Batty, G. D., Deary, I. J., \& Zaninotto, P. (2016). Association of cognitive function with cause-specific mortality in middle and older age: Follow-up of participants in the english longitudinal study of ageing. American Journal of Epidemiology, 183(3), 183-190. https://doi.org/10.1093/aje/kwv139

Baune, B. T., Miller, R., McAfoose, J., Johnson, M., Quirk, F., \& Mitchell, D. (2010). The role of cognitive impairment in general functioning in major depression. Psychiatry Research, 176(2-3), 183-189. https://doi.org/10.1016/j.psychres.2008.12.001

Belsky, D. W., Moffitt, T. E., Corcoran, D. L., Domingue, B., Harrington, H. L., Hogan, S., ... Caspi, A. (2016). The Genetics of Success: How Single-Nucleotide Polymorphisms Associated With Educational Attainment Relate to Life-Course Development. Psychological Science, 27(7), 957-972. https://doi.org/10.1177/0956797616643070

Briley, D. A., \& Tucker-Drob, E. M. (2019). What do the genetics of education tell us about learning? 
https://doi.org/https://bold.expert/what-do-the-genetics-of-education-tell-us-about-learning/

Bulik-Sullivan, B., Finucane, H. K., Anttila, V., Gusev, A., Day, F. R., Loh, P. R., ... Neale, B. M. (2015). An

atlas of genetic correlations across human diseases and traits. Nature Genetics, 47(11), 1236-1241.

https://doi.org/10.1038/ng.3406

Cain, K., \& Oakhill, J. (2011). Matthew effects in young readers: Reading comprehension and reading experience aid vocabulary development. Journal of Learning Disabilities, 44(5), 431-443. https://doi.org/10.1177/0022219411410042

Calvin, C. M., Deary, I. J., Webbink, D., Smith, P., Fernandes, C., Lee, S. H., .. Peter, M. V. (2012). Multivariate genetic analyses of cognition and academic achievement from two population samples of 174,000 and 166,000 school children. Behavior Genetics, 42(5), 699-710. https://doi.org/10.1007/s10519012-9549-7

Carroll, J. B. (John B. (1993). Human cognitive abilities : a survey of factor-analytic studies. Cambridge University Press.

Caspi, A., Houts, R. M., Belsky, D. W., Harrington, H., Hogan, S., Ramrakha, S., ... Moffitt, T. E. (2016). Childhood forecasting of a small segment of the population with large economic burden. Nature Human Behaviour, 1(December), 1-10. https://doi.org/10.1038/s41562-016-0005

Ceci, S. J. (1991). How much does schooling influence general intelligence and its cognitive components? A reassessment of the evidence. Developmental Psychology, 27(5), 703-722. https://doi.org/10.1037/00121649.27.5.703

Chabris, C. F., Hebert, B. M., Benjamin, D. J., Beauchamp, J., Cesarini, D., van der Loos, M., ... Laibson, D. (2012). Most Reported Genetic Associations With General Intelligence Are Probably False Positives. Psychological Science, 23(11), 1314-1323. https://doi.org/10.1177/0956797611435528

Chabris, C. F., Lee, J. J., Benjamin, D. J., Beauchamp, J. P., Glaeser, E. L., Borst, G., ... Laibson, D. I. (2013). Why it is hard to find genes associated with social science traits: Theoretical and empirical considerations. American Journal of Public Health, 103(SUPPL.1), 152-166. https://doi.org/10.2105/AJPH.2013.301327

Chabris, C. F., Lee, J. J., Cesarini, D., Benjamin, D. J., \& Laibson, D. I. (2015). The Fourth Law of Behavior Genetics. Current Directions in Psychological Science, 24(4), 304-312. https://doi.org/10.1177/0963721415580430

Chamorro-Premuzic, T., Harlaar, N., Greven, C. U., \& Plomin, R. (2010). More than just IQ: A longitudinal examination of self-perceived abilities as predictors of academic performance in a large sample of UK twins. Intelligence, 38(4), 385-392. https://doi.org/10.1016/j.intell.2010.05.002

Cheesman, R., Hunjan, A., Coleman, J. R. I., Ahmadzadeh, Y., Plomin, R., McAdams, T. A., ... Breen, G. (2019). Comparison of adopted and non-adopted individuals reveals gene-environment interplay for education in the UK Biobank. BioRxiv, 1-29. Retrieved from http://dx.doi.org/10.1101/707695 
Conley, D., Rauscher, E., Dawes, C., Magnusson, P. K. E., \& Siegal, M. L. (2013). Heritability and the equal environments assumption: evidence from multiple samples of misclassified twins. Behavior Genetics, 43(5), 415-426. https://doi.org/10.1007/s 10519-013-9602-1

Costa, P. T., \& McCrae, R. R. (1992). Four ways five factors are basic. Personality and Individual Differences, 13(6), 667-673. https://doi.org/10.1016/0191-8869(92)90237-J

Cowan, R., Hurry, J., \& Midouhas, E. (2018). The relationship between learning mathematics and general cognitive ability in primary school. British Journal of Developmental Psychology, 36(2), 277-284. https://doi.org/10.1111/bjdp.12200

Credé, M., Tynan, M. C., \& Harms, P. D. (2017). Much ado about grit: A meta-analytic synthesis of the grit literature. Journal of Personality and Social Psychology, Vol. 113, pp. 492-511. https://doi.org/10.1037/pspp0000102

Cutler, D. M., \& Lleras-Muney, A. (2012). Education and Health: Insights from International Comparisons. https://doi.org/10.3386/w17738

Daly, M., Egan, M., \& O’Reilly, F. (2015). Childhood general cognitive ability predicts leadership role occupancy across life: Evidence from 17,000 cohort study participants. Leadership Quarterly, 26(3), 323341. https://doi.org/10.1016/j.leaqua.2015.03.006

Daucourt, M. C., Erbeli, F., Little, C. W., Haughbrook, R., Hart, A., Daucourt, M. C., ... Haughbrook, R. (2019). Scientific Studies of Reading A Meta-Analytical Review of the Genetic and Environmental Correlations between Reading and Attention-Deficit / Hyperactivity Disorder Symptoms and Reading and Math A Meta-Analytical Review of the Genetic and Environmental. Scientific Studies of Reading, O(0), 134. https://doi.org/10.1080/10888438.2019.1631827

Davies, G., Lam, M., Harris, S. E., Trampush, J. W., Luciano, M., Hill, W. D., .. Deary, I. J. (2018). Study of 300,486 individuals identifies 148 independent genetic loci influencing general cognitive function. Nature Communications, 9(1), 2098. https://doi.org/10.1038/s41467-018-04362-X

Davis, O. S. P., Kovas, Y., Harlaar, N., Busfield, P., McMillan, A., Frances, J., ... Plomin, R. (2008). Generalist genes and the Internet generation: Etiology of learning abilities by web testing at age 10. Genes, Brain and Behavior, 7(4), 455-462. https://doi.org/10.1111/j.1601-183X.2007.00370.X

de Zeeuw, E. L., de Geus, E. J. C., \& Boomsma, D. I. (2015). Meta-analysis of twin studies highlights the importance of genetic variation in primary school educational achievement. Trends in Neuroscience and Education, 4(3), 69-76. https://doi.org/10.1016/j.tine.2015.06.001

Deary, I. J. (2013). Intelligence. Current Biology, 23(16), R673-R676. https://doi.org/10.1093/oso/9780198790501.003.0038

Deary, Ian J., Harris, S. E., \& Hill, W. D. (2019). What genome-wide association studies reveal about the association between intelligence and physical health, illness, and mortality. Current Opinion in 
Psychology, 27, 6-12. https://doi.org/10.1016/j.copsyc.2018.07.005

Deary, Ian J., \& Johnson, W. (2010). Intelligence and education: Causal perceptions drive analytic processes and therefore conclusions. International Journal of Epidemiology, 39(5), 1362-1369. https://doi.org/10.1093/ije/dyq072

Deary, Ian J., Strand, S., Smith, P., \& Fernandes, C. (2007). Intelligence and educational achievement. Intelligence, 35(1), 13-21. https://doi.org/10.1016/j.intell.2006.02.001

Deary, Ian J., Weiss, A., \& Batty, G. D. (2010). Intelligence and personality as predictors of illness and death: How researchers in differential psychology and chronic disease epidemiology are collaborating to understand and address health inequalities. Psychological Science in the Public Interest, Supplement, 11(2), 53-79. https://doi.org/10.1177/1529100610387081

Deary, Ian J., Whalley, L. J., Lemmon, H., Crawford, J. R., \& Starr, J. M. (2000). The stability of individual differences in mental ability from childhood to old age: Follow-up of the 1932 Scottish mental survey. Intelligence, 28(1), 49-55. https://doi.org/10.1016/S0160-2896(99)00031-8

Deary, Ian J, Yang, J., Davies, G., Harris, S. E., Tenesa, A., Liewald, D., ... Visscher, P. M. (2012). Genetic contributions to stability and change in intelligence from childhood to old age. Nature, 482. https://doi.org/10.1038/nature10781

Dolan, C. V., Huijskens, R. C. A., Minică, C. C., Neale, M. C., \& Boomsma, D. I. (2019). Incorporating polygenic scores in the twin model to estimate genotype-environment covariance: exploration of statistical power. BioRxiv, 1-32. Retrieved from doi: http://dx.doi.org/10.1101/702738

Duckworth, A.L., \& Gross, J. J. (2014). Self-Control and Grit: Related but Separable Determinants of Success. Current Directions in Psychological Science, 23(5), 319-325. https://doi.org/10.1177/0963721414541462.Self-Control

Duckworth, Angela L., Peterson, C., Matthews, M. D., \& Kelly, D. R. (2007). Grit: Perseverance and passion for long-term goals. Journal of Personality and Social Psychology, 92(6), 1087-1101. https://doi.org/10.1037/0022-3514.92.6.1087

Dudbridge, F. (2013). Power and Predictive Accuracy of Polygenic Risk Scores. PLoS Genetics, 9(3). https://doi.org/10.1371/journal.pgen.1003348

Duncan, L., \& Keller, M. (2011). A Critical Review of the First 10 Years of Candidate Gene-by-Environmental Interaction Research in Psychiatry. Am J Psychiatry, 168(10), 1041-1049. https://doi.org/10.1176/appi.ajp.2011.11020191.A

Emmanuel, P., \& von Schantz, M. (2018). Absence of morningness alleles in non-European populations. Chronobiology International, O0(00), 1-4. https://doi.org/10.1080/07420528.2018.1506928

Engelhardt, L E, Church, J. A., Harden, K. P., \& Tucker-Drob, E. M. (2018). Accounting for the shared environment in cognitive abilities and academic achievement with measured socioecological contexts. 
(May), 1-16. https://doi.org/10.1111/desc.12699

Engelhardt, Laura E., Briley, D. A., Mann, F. D., Harden, K. P., \& Tucker-Drob, E. M. (2015). Genes Unite

Executive Functions in Childhood. Psychological Science, 0956797615577209.

https://doi.org/10.1177/0956797615577209

Engelhardt, Laura E, Mann, F. D., Briley, D. A., Church, J. A., Harden, K. P., Tucker-drob, E. M., ... Tuckerdrob, E. M. (2016). Journal of Experimental Psychology: General Strong Genetic Overlap Between Executive Functions and Intelligence Strong Genetic Overlap Between Executive Functions and Intelligence.

Ferrer, E., \& McArdle, J. J. (2004). An Experimental Analysis of Dynamic Hypotheses about Cognitive Abilities and Achievement from Childhood to Early Adulthood. Developmental Psychology, 40(6), 935952. https://doi.org/10.1037/0012-1649.40.6.935

Friedman, N. P., \& Miyake, A. (2017). Unity and diversity of executive functions: Individual differences as a window on cognitive structure. Cortex, 86, 186-204. https://doi.org/10.1016/j.cortex.2016.04.023

Furnham, A., \& Cheng, H. (2016). Childhood Cognitive Ability Predicts Adult Financial Well-Being. Journal of Intelligence, 5(1), 3. https://doi.org/10.3390/jintelligence5010003

Garon-Carrier, G., Boivin, M., Guay, F., Kovas, Y., Dionne, G., Lemelin, J. P., ... Tremblay, R. E. (2016). Intrinsic Motivation and Achievement in Mathematics in Elementary School: A Longitudinal Investigation of Their Association. Child Development, 87(1), 165-175. https://doi.org/10.1111/cdev.12458

Gottschling, J., Spengler, M., Spinath, B., \& Spinath, F. M. (2012). The prediction of school achievement from a behavior genetic perspective: Results from the German twin study on Cognitive Ability, Self-Reported Motivation, and School Achievement (CoSMoS). Personality and Individual Differences, 53(4), 381-386. https://doi.org/10.1016/j.paid.2012.01.020

Greven, C. U., Harlaar, N., Kovas, Y., Chamorro-Premuzic, T., \& Plomin, R. (2009). School Achievement Is Predicted by Self-Perceived Abilities-But for genetic rather than enviornmental reasons. Psychological Science, 20(6), 753-763.

Grotzinger, A. D., Rhemtulla, M., de Vlaming, R., Ritchie, S. J., Mallard, T. T., Hill, W. D., ... Tucker-Drob, E. M. (2019). Genomic structural equation modelling provides insights into the multivariate genetic architecture of complex traits. Nature Human Behaviour, 3(5), 513-525. https://doi.org/10.1038/s41562019-0566-X

Guay, F., Ratelle, C. F., Roy, A., \& Litalien, D. (2010). Academic self-concept, autonomous academic motivation, and academic achievement: Mediating and additive effects. Learning and Individual Differences, 20(6), 644-653. https://doi.org/10.1016/j.lindif.2010.08.001

Guez, A., Panaïotis, T., Peyre, H., \& Ramus, F. (2018). Predictors of the IQ-achievement gap in France: A longitudinal analysis. Intelligence, 69(May), 104-116. https://doi.org/10.1016/j.intell.2018.05.008 
Harlaar, N, Hayiou-Thomas, M. E., \& Plomin, R. (2009). Reading and General Cognitive Ability: A Multivariate Analysis of 7-Year-Old Twins. Scientific Studies of Reading, 9(3), 197-218. https://doi.org/https://doi.org/10.1207/s1532799xssr0903_2

Harlaar, Nicole, Dale, P. S., \& Plomin, R. (2007). From Learning to Read to Reading to Learn : Substantial and Stable Genetic Influence. 78(1), 116-131.

Haworth, C. M. A., Wright, M. J., Luciano, M., Martin, N. G., De Geus, E. J. C., Van Beijsterveldt, C. E. M., ... Plomin, R. (2010). The heritability of general cognitive ability increases linearly from childhood to young adulthood. Molecular Psychiatry, 15(11), 1112-1120. https://doi.org/10.1038/mp.2009.55

Heckman, J. J., Stixrud, J., \& Urzua, S. (2006). The effects of cognitive and noncognitive abilities on labor market outcomes and social behavior. Journal of Labor Economics, 24(3), 411-482.

Hill, W. D., Marioni, R. E., Maghzian, O., Ritchie, S. J., Hagenaars, S. P., McIntosh, A. M., ... Deary, I. J. (2018). A combined analysis of genetically correlated traits identifies 187 loci and a role for neurogenesis and myelination in intelligence. Molecular Psychiatry, 1-13. https://doi.org/10.1038/s41380-017-0001-5

Johnson, W., Deary, I. J., \& Iacono, W. G. (2009). Genetic and environmental transactions underlying educational attainment. Intelligence, 37(5), 466-478. https://doi.org/10.1016/j.intell.2009.05.006

Kalechstein, A. D., Newton, T. F., \& van Gorp, W. G. (2003). Neurocognitive Functioning is Associated ith Employment Status: A Quantitative Review. Journal of Clinical and Experimental Neuropsychology (Neuropsychology, Development and Cognition: Section A), 25(8), 1186-1191. https://doi.org/10.1076/jcen.25.8.1186.16723

Kaufman, S. B., Reynolds, M. R., Liu, X., Kaufman, A. S., \& McGrew, K. S. (2012). Are cognitive g and academic achievement $g$ one and the same $\mathrm{g}$ ? An exploration on the Woodcock-Johnson and Kaufman tests. Intelligence, 40(2), 123-138. https://doi.org/10.1016/j.intell.2012.01.009

Kendler, K. S., Kessler, R. C., Neale, M. C., Heath, A. C., \& Eaves, L. J. (1993). The prediction of major depression in women: Toward an integrated etiologic model. American Journal of Psychiatry, 150(8), 1139-1148. https://doi.org/10.1176/ajp.150.8.1139

Kendler, K. S., Neale, M. C., Kessler, R. C., Heath, A. C., \& Eaves, L. . (1993). A twin study of recent life events and difficulties. Archives of General Psychiatry, 50, 789-796.

Knopik, V. S., Neiderhiser, J. M., Defries, J. C., \& Plomin, R. (2016). Behavioral Genetics (Seventh). Macmillan Higher Education.

Koellinger, P. D., \& Harden, K. P. (2018). Using nature to understand nurture: Genetic associations show how parenting matters for children's education. Science, 359(6374), 386-387. https://doi.org/10.1126/science.aar6429

Kong, A., Thorleifsson, G., Frigge, M. L., Vilhjalmsson, B., Young, A. I., Thorgeirsson, T. E., ... Stefansson, K. (2018). The nature of nurture: Effects of parental genotypes. Science, 359(January), 424-428. 
https://doi.org/10.1101/219261

Kovas, Y., Haworth, C. M. A., Harlaar, N., Petrill, S. A., Dale, P. S., \& Plomin, R. (2007). Overlap and specificity of genetic and environmental influences on mathematics and reading disability in 10-year-old twins. Journal of Child Psychology and Psychiatry and Allied Disciplines, 48(9), 914-922. https://doi.org/10.1111/j.1469-7610.2007.01748..x

Kovas, Y, Harlaar, N., Petrill, S. A., \& Plomin, R. (2005). “Generalist genes” and mathematics in 7-year-old twins. Intelligence, 33, 473-489. https://doi.org/10.1016/j.intell.2005.05.002

Kovas, Yulia, Garon-Carrier, G., Boivin, M., Petrill, S. A., Plomin, R., Malykh, S. B., ... Vitaro, F. (2015). Why children differ in motivation to learn: Insights from over 13,000 twins from 6 countries. Personality and Individual Differences, 80, 51-63. https://doi.org/10.1016/j.paid.2015.02.006

Kovas, Yulia, Voronin, I., Kaydalov, A., Malykh, S. B., Dale, P. S., \& Plomin, R. (2013). Literacy and numeracy are more heritable than intelligence in primary school. Psychological Science, 24(10), 20482056. https://doi.org/10.1177/0956797613486982

Krapohl, E, Patel, H., Newhouse, S., Curtis, C. J., von Stumm, S., Dale, P. S., .. Plomin, R. (2017). Multipolygenic score approach to trait prediction. Molecular Psychiatry, (June), 1-7. https://doi.org/10.1038/mp.2017.163

Krapohl, Eva, Rimfeld, K., Shakeshaft, N. G., Trzaskowski, M., McMillan, A., Pingault, J.-B. J.-B., ... Plomin, R. (2014). The high heritability of educational achievement reflects many genetically influenced traits, not just intelligence. Proceedings of the National Academy of Sciences, 111(42), 15273-15278. https://doi.org/10.1073/pnas.1408777111

Latvala, A., Kuja-Halkola, R., D’Onofrio, B. M., Larsson, H., \& Lichtenstein, P. (2016). Cognitive ability and risk for substance misuse in men: genetic and environmental correlations in a longitudinal nation-wide family study. Addiction, 111(10), 1814-1822. https://doi.org/10.1111/add.13440

Lawlor, D. A., Tilling, K., \& Smith, G. D. (2016). Triangulation in aetiological epidemiology. International Journal of Epidemiology, 45(6), 1866-1886. https://doi.org/10.1093/ije/dyw314

Lee, J. J., Wedow, R., Okbay, A., Kong, E., Maghzian, O., Zacher, M., ... Cesarini, D. (2018). Gene discovery and polygenic prediction from a genome-wide association study of educational attainment in 1.1 million individuals. Nature Genetics, 50(8), 1112-1121. https://doi.org/10.1038/s41588-018-0147-3

Lemelin, J. P., Boivin, M., Forget-Dubois, N., Dionne, G., Séguin, J. R., Brendgen, M., ... Pérusse, D. (2007). The genetic-environmental etiology of cognitive school readiness and later academic achievement in early childhood. Child Development, 78(6), 1855-1869. https://doi.org/10.1111/j.1467-8624.2007.01103.x

Ligthart, L., \& Boomsma, D. I. (2012). Causes of comorbidity: Pleiotropy or causality? shared genetic and environmental influences on migraine and neuroticism. Twin Research and Human Genetics, 15(2), 158165. https://doi.org/10.1375/twin.15.2.158 
Lubinski, D. (2004). Introduction to the Special Section on Cognitive Abilities: 100 Years After Spearman's (1904) “'General Intelligence,' Objectively Determined and Measured.” Journal of Personality and Social Psychology, 86(1), 96-111. https://doi.org/10.1037/0022-3514.86.1.96

Luo, Y. L. L., Haworth, C. M. A., \& Plomin, R. (2010). A novel approach to Genetic and Environmental Analysis of Cross-Lagged Associations Over Time: The Cross-Lagged Relationship Between SelfPerceived Abilities and School Achievement is Mediated by Genes as Well as the Environment. Twin Res Hum Genet, 13(5), 631-637. https://doi.org/10.1111/j.1747-0285.2012.01428.x.Identification

Luo, Y. L. L., Kovas, Y., Haworth, C. M. A., \& Plomin, R. (2011). The etiology of mathematical selfevaluation and mathematics achievement: Understanding the relationship using a cross-lagged twin study from ages 9 to 12. Learning and Individual Differences, 21(6), 710-718. https://doi.org/10.1016/j.lindif.2011.09.001

Lynch, M., \& Walsh, B. (1998). Genetics and Analysis of Quantitative Traits. In Genetics and anaylsis of quantitative traits. Sunderland, MA: Sinauer Associates.

Ma, X., Xu, J., \& Xu, J. (2004). The causal ordering of mathematics anxiety and mathematics achievement: a longitudinal panel analysis. Journal of Adolescence, 27(2), 165-179. https://doi.org/10.1016/j.adolescence.2003.11.003

Mackintosh, N., \& Mackintosh, N. (2011). IQ and Human Intelligence. Oxford University Press, UK.

Maher, B. (2008). Personal genomes: The case of the missing heritability. Nature, 456(7218), 18-21. https://doi.org/10.1038/456018a

Malanchini, M., Engelhardt, L. E., Grotzinger, A. D., Harden, K. P., \& Tucker-Drob, E. M. (2018). “Same But Different": Associations Between Multiple Aspects of Self-Regulation, Cognition, and Academic Abilities. Journal of Personality and Social Psychology. https://doi.org/10.1037/pspp0000224

Malanchini, M., Tosto, M. G., Garfield, V., Dirik, A., Czerwik, A., Arden, R., ... Kovas, Y. (2016). Preschool Drawing and School Mathematics: The Nature of the Association. Child Development, 87(3), 929-943. https://doi.org/10.1111/cdev.12520

Malanchini, M., Wang, Z., Voronin, I., Schenker, V. J., Plomin, R., Petrill, S. A., \& Kovas, Y. (2017). Reading self-perceived ability, enjoyment and achievement: A genetically informative study of their reciprocal links over time. Developmental Psychology, 53(4). https://doi.org/10.1037/dev0000209

Manolio, T. A. et al. (2009). Finding the missing heritability of complex diseases. Nat Reviews, Vol. 461, pp. 747-753. https://doi.org/nature08494 [pii] \r10.1038/nature08494

Manuck, S. B., \& McCaffery, J. M. (2014). Gene-environment interaction. Annual Review of Psychology, 65, 41-70. https://doi.org/10.1038/gim.2015.126

Martin, A. R., Kanai, M., Kamatani, Y., Okada, Y., Neale, B. M., \& Daly, M. J. (2019). Clinical use of current polygenic risk scores may exacerbate health disparities. Nature Genetics, 51(4), 584-591. 
https://doi.org/10.1038/s41588-019-0379-X

Martin, N., Boomsma, D., \& Machin, G. (1997). A twin-pronged attack on complex traits. Nature Genetics, 17(4), 387-392. https://doi.org/10.1038/ng1297-387

Martin, N. G., \& Eaves, L. J. (1977). Stages; the First To Determine the Genetical and Environmental Model. Most, 38, 79-95.

McCoach, D. B., Yu, H., Gottfried, A. W., \& Gottfried, A. E. (2017). Developing talents: A longitudinal examination of intellectual ability and academic achievement. High Ability Studies, 28(1), 7-28. https://doi.org/10.1080/13598139.2017.1298996

McIntosh, A. M., Sullivan, P. F., \& Lewis, C. M. (2019). Uncovering the Genetic Architecture of Major Depression. Neuron, 102(1), 91-103. https://doi.org/10.1016/j.neuron.2019.03.022

Mollon, J., David, A. S., Zammit, S., Lewis, G., \& Reichenberg, A. (2018). Course of Cognitive Development From Infancy to Early Adulthood in the Psychosis Spectrum. JAMA Psychiatry, 06510. https://doi.org/10.1001/jamapsychiatry.2017.4327

Montez, J. K., \& Hayward, M. D. (2014). Cumulative Childhood Adversity, Educational Attainment, and Active Life Expectancy Among U. S . Adults. 413-435. https://doi.org/10.1007/s13524-013-0261-x

Morris, T. T., Smith, G. D., Berg, G. Van den, \& Davies, N. M. (2018). Investigating the phenotypic consistency and genetic architecture of noncognitive skills. BioRxiv, 470682. https://doi.org/10.1101/470682

Muenks, K., Wigfield, A., Yang, J. S., \& O’Neal, C. R. (2017). How true is grit? Assessing its relations to high school and college students' personality characteristics, self-regulation, engagement, and achievement. Journal of Educational Psychology, 109(5), 599-620. https://doi.org/10.1037/edu0000153

OECD. (2018). Education at a Glance 2018. https://doi.org/10.1787/eag-2018-en

Okbay, A., Beauchamp, J. P., Fontana, M. A., Lee, J. J., Pers, T. H., Rietveld, C. A., ... Benjamin, D. J. (2016). Genome-wide association study identifies 74 loci associated with educational attainment. Nature, 533(7604), 539-542. https://doi.org/10.1038/nature17671

Okbay, A., Beauchamp, J. P., Fontana, M., Lee, J. J., Pers, T. ., Rietveld, C. A., ... Pickrell, J. K. (2016). Genome-wide association study identifies 74 loci associated with educational attainment. Nature, 533(7604), 539-542. https://doi.org/10.1038/nature17671

Oreopoulos, P., \& Salvanes, K. G. (2011). Priceless: The Nonpecuniary Benefits of Schooling. Journal of Economic Perspectives, 25(1), 159-184. https://doi.org/10.1257/jep.25.1.159

Pepper, G. V., \& Nettle, D. (2017). The behavioural constellation of deprivation: Causes and consequences. Behavioral and Brain Sciences, 40(2017). https://doi.org/10.1017/S0140525X1600234X

Petrill, S. A., \& Wilkerson, B. (2000). Intelligence and Achievement: A Behavioral Genetic Perspective. Educational Psychology Review, 12(2), 185-199. https://doi.org/10.1023/A:1009023415516 
Petrill, S., Logan, J., Hart, S., Vincent, P., Thompson, L., Kovas, Y., \& Plomin, R. (2012). Math Fluency Is Etiologically Distinct From Untimed Math Performance, Decoding Fluency, and Untimed Reading Performance: Evidence From a Twin Study. Journal of Learning Disabilities, 45(4), 371-381. https://doi.org/10.1177/0022219411407926

Plomin, R., \& Deary, I. J. (2015). Genetics and intelligence differences: Five special findings. Molecular Psychiatry, 20(1), 98-108. https://doi.org/10.1038/mp.2014.105

Plomin, R., DeFries, J. C., \& Loehlin, J. C. (1977). Genotype-Environment Interaction and Correlation in the Analysis of Human Behavior. Psychological Bulletin, 84, 309-322.

Plomin, Robert. (2014). Genotype-Environment Correlation in the Era of DNA. Behavior Genetics, 44(6), 629638. https://doi.org/10.1007/s10519-014-9673-7

Plomin, Robert. (2019). Blueprint: How DNA makes us who we are. Mit Press.

Plomin, Robert, \& Bergeman, C. S. (1991). The nature of nurture: Genetic influence on "environmental" measures. Behavioral and Brain Sciences, 14(3), 373-386. https://doi.org/10.1017/S0140525X00070278

Plomin, Robert, \& Kovas, Y. (2005). Generalist Genes and Learning Disabilities. Psychological Bulletin, 131(4), 592-617. https://doi.org/10.1037/0033-2909.131.4.592

Plomin, Robert, \& Von Stumm, S. (2018). The new genetics of intelligence. Nature Reviews Genetics, 19(3), 148-159. https://doi.org/10.1038/nrg.2017.104

Polderman, T. J. C., Benyamin, B., De Leeuw, C. A., Sullivan, P. F., Van Bochoven, A., Visscher, P. M., \& Posthuma, D. (2015). Meta-analysis of the heritability of human traits based on fifty years of twin studies. Nature Genetics, 47(7), 702-709. https://doi.org/10.1038/ng.3285

Popejoy, A. B., \& Fullerton, S. M. (2016). Genomics is failing on diversity. Nature, 538(7624), 161-164. https://doi.org/10.1038/538161a

Richardson, M., Abraham, C., \& Bond, R. (2012). Psychological correlates of university students' academic performance: A systematic review and meta-analysis. Psychological Bulletin, Vol. 138, pp. 353-387. https://doi.org/10.1037/a0026838

Rietveld, C. A. et al. (2013). GWAS of 126,559 Individuals Identifies Genetic Variants Associated with Educational Attainment. Science, 340(6139), 1467-1471. https://doi.org/DOI: 10.1126/science.1235488

Rimfeld, K., Malanchini, M., Krapohl, E., Hannigan, L. J., Dale, P. S., Plomin, R., ... Centre, D. P. (2018). The stability of educational achievement across school years is largely explained by genetic factors. $N p j$ Science of Learning, 3.

Rimfeld, Kaili, Ayorech, Z., Dale, P. S., Kovas, Y., \& Plomin, R. (2016). Genetics affects choice of academic subjects as well as achievement. Scientific Reports, 6(December 2015), 26373. https://doi.org/10.1038/srep26373

Rimfeld, Kaili, Kovas, Y., Dale, P. S., \& Plomin, R. (2015). Pleiotropy across academic subjects at the end of 
compulsory education. Scientific Reports, 5, 11713. https://doi.org/10.1038/srep11713

Rimfeld, Kaili, Kovas, Y., Dale, P. S., \& Plomin, R. (2016). True Grit and Genetics: Predicting Academic Achievement From Personality. Journal of Personality and Social Psychology, 111(5), No Pagination Specified. https://doi.org/10.1037/pspp0000089

Rimfeld, Kaili, Krapohl, E., Trzaskowski, M., Coleman, J. R. I., Selzam, S., Dale, P. S., ... Plomin, R. (2018).

Genetic influence on social outcomes during and after the Soviet era in Estonia. Nature Human Behaviour, 2(4), 269-275. https://doi.org/10.1038/s41562-018-0332-5

Rimfeld, Kaili, Malanchini, M., Hannigan, L. J., Dale, P. S., Allen, R., Hart, S. A., \& Plomin, R. (2019).

Teacher assessments during compulsory education are as reliable, stable and heritable as standardized test scores. Journal of Child Psychology and Psychiatry and Allied Disciplines. https://doi.org/10.1111/jcpp.13070

Rimfeld, Kaili, Malanchini, M., Krapohl, E., Hannigan, L. J., Dale, P. S., Plomin, R., ... Centre, D. P. (2018). The stability of educational achievement across school years is largely explained by genetic factors. Under Review, (July), 1-10. https://doi.org/10.1038/s41539-018-0030-0

Ritchie, S. J., \& Bates, T. C. (2013). Enduring Links From Childhood Mathematics and Reading Achievement to Adult Socioeconomic Status. Psychological Science, 24(7), 1301-1308. https://doi.org/10.1177/0956797612466268

Ritchie, Stuart J., Bates, T. C., \& Deary, I. J. (2015). Is education associated with improvements in general cognitive ability, or in specific skills? Developmental Psychology, 51(5), 573-582. https://doi.org/10.1037/a0038981

Ritchie, Stuart J., Bates, T. C., Der, G., Starr, J. M., \& Deary, I. J. (2013). Education is associated with higher later life IQ scores, but not with faster cognitive processing speed. Psychology and Aging, 28(2), 515-521. https://doi.org/10.1037/a0030820

Ritchie, Stuart J., Bates, T. C., \& Plomin, R. (2015). Does Learning to Read Improve Intelligence? A Longitudinal Multivariate Analysis in Identical Twins From Age 7 to 16. Child Development, 86(1), 2336. https://doi.org/10.1111/cdev.12272

Ritchie, Stuart J., \& Tucker-Drob, E. M. (2018). How Much Does Education Improve Intelligence? A MetaAnalysis. Psychological Science, 29(8), 1358-1369. https://doi.org/10.1177/0956797618774253

Roth, B., Becker, N., Romeyke, S., Schäfer, S., Domnick, F., \& Spinath, F. M. (2015). Intelligence and school grades: A meta-analysis. Intelligence, 53, 118-137. https://doi.org/10.1016/j.intell.2015.09.002

Rowe, D. C., Jacobson, K. C., \& Van Den Oord, E. J. C. G. (1999). Genetic and environmental influences on vocabulary IQ: Parental education level as moderator. Child Development, 70(5), 1151-1162. https://doi.org/10.1111/1467-8624.00084

Røysamb, E., \& Tambs, K. (2016). The beauty, logic and limitations of twin studies. Norsk Epidemiologi, 26(1- 
2), 35-46. https://doi.org/10.5324/nje.v26i1-2.2014

Savage, J. E., Jansen, P. R., Stringer, S., Watanabe, K., Bryois, J., de Leeuw, C. A., ... Posthuma, D. (2018).

Genome-wide association meta-analysis in 269,867 individuals identifies new genetic and functional links to intelligence. Nature Genetics, 50(7), 912-919. https://doi.org/10.1038/s41588-018-0152-6

Savage, J. E., Jansen, P. R., Stringer, S., Watanabe, K., Bryois, J., Leeuw, C. A. de, .. Posthuma, D. (2018).

GWAS meta-analysis $(\mathrm{N}=279,930)$ identifies new genes and functional links to intelligence. Nature

Genetics, 50, 912-919. https://doi.org/10.1101/184853

Scarr, S. (1971). Race, Social Class, and IQ. Science, 174(4016), 1285-1295.

Selzam, S., Krapohl, E., Von Stumm, S., O’Reilly, P. F., Rimfeld, K., Kovas, Y., ... Plomin, R. (2017).

Predicting educational achievement from DNA. Molecular Psychiatry, 22(2), 267-272.

https://doi.org/10.1038/mp.2016.107

Selzam, S, Krapohl, E., von Stumm, S., O’Reilly, P. F., Rimfeld, K., Kovas, Y., ... Plomin, R. (2017).

Predicting educational achievement from DNA. Molecular Psychiatry, 22(2), 267-272.

https://doi.org/10.1038/mp.2016.107

Selzam, Saskia, Ritchie, S. J., Pingault, J.-B., Reynolds, C. A., O’Reilly, P. F., \& Plomin, R. (2019). Comparing within- and between-family polygenic score prediction. The American Journal of Human Genetics, 105, 113. https://doi.org/10.1101/605006

Shakeshaft, N. G., Trzaskowski, M., McMillan, A., Rimfeld, K., Krapohl, E., Haworth, C. M. A., ... Plomin, R. (2013). Strong genetic influence on a UK nationwide test of educational achievement at the end of compulsory education at age 16. PLoS ONE, 8(12). https://doi.org/10.1371/journal.pone.0080341

Smith-Woolley, E., Ayorech, Z., Dale, P. S., von Stumm, S., \& Plomin, R. (2018). The genetics of university success. Scientific Reports, 8(1), 1-9. https://doi.org/10.1038/s41598-018-32621-w

Smith-Woolley, E., Selzam, S., \& Plomin, R. (2019). Polygenic Score for Educational Attainment Captures DNA Variants Shared Between Personality Traits and Educational Achievement. Journal of Personality and Social Psychology. https://doi.org/10.1037/pspp0000241

Sniekers, S., Stringer, S., Watanabe, K., Jansen, P. R., Coleman, J. R. I., Krapohl, E., ... Posthuma, D. (2017). Genome-wide association meta- A nalysis of 78,308 individuals identifies new loci and genes influencing human intelligence. Nature Genetics, 49(7), 1107-1112. https://doi.org/10.1038/ng.3869

Snyder, H. R., Miyake, A., \& Hankin, B. L. (2015). Advancing understanding of executive function impairments and psychopathology: bridging the gap between clinical and cognitive approaches. Frontiers in Psychology, 6. https://doi.org/10.3389/fpsyg.2015.00328

Sokolowski, H. M., \& Ansari, D. (2018). Understanding the effects of education through the lens of biology.

Npj Science of Learning, 3(1). https://doi.org/10.1038/s41539-018-0032-y

Spearman, C. (1904). “General Intelligence,” Objectively Determined and Measured Author ( s ): C . 
Spearman Source: The American Journal of Psychology, Vol . 15, No . 2 ( Apr ., 1904 ), pp . 201-292

Published by : University of Illinois Press Stable URL : http://www.jsto. The American Journal of

Psychology, 15(2), 201-292.

Spearman, C. (1927). The abilities of man: Their nature and measurement. Oxford, England: Macmillan.

Sternberg, R. J., Grigorenko, E., \& Bundy, D. A. (2007). The Predictive Value of IQ. Merrill-Palmer Quarterly, 47(1), 1-41. https://doi.org/10.1353/mpq.2001.0005

Tam, V., Patel, N., Turcotte, M., Bossé, Y., Paré, G., \& Meyre, D. (2019). Benefits and limitations of genomewide association studies. Nature Reviews Genetics. https://doi.org/10.1038/s41576-019-0127-1

Tangney, J. P., Baumeister, R. F., \& Boone, A. L. (2004). High Self-Control Predicts Good Adjustment, Less Pathology, Better Grades, and Interpersonal Success. Journal of Personality, 72(2), 271-324. https://doi.org/10.1111/j.0022-3506.2004.00263.x

Thompson, L. A., Detterman, D. K., \& Plomin, R. (1991). Associations between Cognitive Abilities and Scholastic Achievement: Genetic Overlap but Environmental Differences. Psychological Science, 2(3), $158-165$.

Tosto, M. G., Hayiou-Thomas, M. E., Harlaar, N., Prom-Wormley, E., Dale, P. S., \& Plomin, R. (2017). The genetic architecture of oral language, reading fluency, and reading comprehension: A twin study from 7 to 16 years. Developmental Psychology, 53(6), 1115-1129. https://doi.org/10.1037/dev0000297

Tosto, M. G., Malykh, S., Voronin, I., Plomin, R., \& Kovas, Y. (2013). The Etiology of Individual Differences in Maths beyond IQ: Insights from 12-year Old Twins. Procedia - Social and Behavioral Sciences, 86, 429-434. https://doi.org/10.1016/j.sbspro.2013.08.592

Trzaskowski, M., Yang, J., Visscher, P. M., \& Plomin, R. (2014). DNA evidence for strong genetic stability and increasing heritability of intelligence from age 7 to 12. Molecular Psychiatry, 19(3), 380-384. https://doi.org/10.1038/mp.2012.191

Trzaskowski, Maciej, Davis, O. S. P., Defries, J. C., Yang, J., Visscher, P. M., \& Plomin, R. (2013). DNA evidence for strong genome-wide pleiotropy of cognitive and learning abilities. Behavior Genetics, 43(4), 267-273. https://doi.org/10.1007/s10519-013-9594-X

Tucker-Drob, E. M., \& Harden, K. P. (2012). Intellectual Interest Mediates Gene-by-SES Interaction on Adolescent Academic Achievement. Child Development, 83(2), 743-757. https://doi.org/10.1111/j.14678624.2011.01721.x.Intellectual

Tucker-Drob, E. M., \& Harden, K. P. (2014). National GDP, Science Interest and Science Achievement: A Person-by-Nation Interaction. Psychological Science, 25(11), 2047-2057. https://doi.org/10.1177/0956797614548726.National

Tucker-Drob, E. M., \& Harden, K. P. (2017). Behavioral genetic perspective on noncognitive factors and academic achievement. In \& M. T. (Editors) In S. Bouregy, E. Grigorenko, S. Latham (Ed.), Current 
Perspectives in Psychology: Genetics, Ethics and Education. Cambridge University Press.

Tucker-Drob, Elliot M., \& Bates, T. C. (2016). Large Cross-National Differences in Gene $\times$ Socioeconomic

Status Interaction on Intelligence. Psychological Science, 27(2), 138-149.

https://doi.org/10.1177/0956797615612727

Tucker-Drob, Elliot M., \& Briley, D. A. (2012). Socioeconomic status modifies interest-knowledge associations among adolescents. Personality and Individual Differences, 53(1), 9-15.

https://doi.org/10.1016/j.paid.2012.02.004

Tucker-Drob, Elliot M., \& Briley, D. A. (2014). Continuity of genetic and environmental influences on cognition across the life span: A meta-analysis of longitudinal twin and adoption studies. Psychological Bulletin, 140(4), 949-979. https://doi.org/10.1037/a0035893

Tucker-Drob, Elliot M., Briley, D. A., Engelhardt, L. E., Mann, F. D., \& Harden, K. P. (2016). Geneticallymediated associations between measures of childhood character and academic achievement. Journal of Personality and Social Psychology, 111(5), 790-815. https://doi.org/10.1037/pspp0000098

Tucker-Drob, Elliot M., Briley, D. A., \& Harden, K. P. (2013). Genetic and Environmental Influences on Cognition Across Development and Context. Current Directions in Psychological Science, 22(5), 349355. https://doi.org/10.1177/0963721413485087

Turkheimer, E. (1998). Heritability and Biological Explanation. Psychological Review, 105(4), 782-791. https://doi.org/10.1037/0033-295X.105.4.782-791

Turkheimer, E. (2016). Weak Genetic Explanation 20 Years Later: Reply to Plomin et al. (2016). Perspectives on Psychological Science, 11(1), 24-28. https://doi.org/10.1177/1745691615617442

Turley, P., Walters, R. K., Maghzian, O., Okbay, A., Lee, J. J., Fontana, M. A., ... Pitts, S. J. (2018). Multi-trait analysis of genome-wide association summary statistics using MTAG. Nature Genetics, 50(2), $229-237$. https://doi.org/10.1038/s41588-017-0009-4

Visscher, P. M., Brown, M. A., McCarthy, M. I., \& Yang, J. (2012). Five years of GWAS discovery. American Journal of Human Genetics, 90(1), 7-24. https://doi.org/10.1016/j.ajhg.2011.11.029

Visscher, P. M., Wray, N. R., Zhang, Q., Sklar, P., McCarthy, M. I., Brown, M. A., \& Yang, J. (2017). 10 Years of GWAS Discovery: Biology, Function, and Translation. American Journal of Human Genetics, 101(1), 5-22. https://doi.org/10.1016/j.ajhg.2017.06.005

Vitaro, F., Brendgen, M., \& Arseneault, L. (2009). The discordant MZ-twin method: One step closer to the holy grail of causality. International Journal of Behavioral Development, 33(4), 376-382. https://doi.org/10.1177/0165025409340805

von Stumm, S., Smith-Woolley, E., Ayorech, Z., McMillan, A., Rimfeld, K., Dale, P. S., \& Plomin, R. (2019). Predicting educational achievemnt from genomic measures and socioeconomic status. In BioRxiv. https://doi.org/http://dx.doi.org/10.1101/538108 
von Stumm, Sophie, Hell, B., \& Chamorro-Premuzic, T. (2011). The hungry mind: Intellectual curiosity is the third pillar of academic performance. Perspectives on Psychological Science, 6(6), 574-588. https://doi.org/10.1177/1745691611421204

Wainschtein, P., \& et al. (2019). Recovery of trait heritability from whole genome sequence data Visscher 2019.pdf. BioRxiv, 1-23.

Wang, Z., Shakeshaft, N., Schofield, K., \& Malanchini, M. (2018). Anxiety is not enough to drive me away: A latent profile analysis on math anxiety and math motivation. PLoS ONE, 13(2). https://doi.org/10.1371/journal.pone.0192072

Watkins, M. W., Lei, P. W., \& Canivez, G. L. (2007). Psychometric intelligence and achievement: A crosslagged panel analysis. Intelligence, 35(1), 59-68. https://doi.org/10.1016/j.intell.2006.04.005

Wechsler, D. (2003). Wechsler Intelligence Scale for Children-Fourth Edition, Technical Manual. San Antonio, TX: Psychological Corportation.

Wechsler, D. (2011). Wechsler Abbreviated Scale of Intelliegence (2nd editio). Bloomington, MN: Pearson.

West, M. R., Kraft, M. A., Finn, A. S., Martin, R. E., Duckworth, A. L., Gabrieli, C. F. O., \& Gabrieli, J. D. E. (2016). Promise and Paradox. Educational Evaluation and Policy Analysis, 38(1), 148-170. https://doi.org/10.3102/0162373715597298

Yang, J., Lee, S. H., Goddard, M. E., \& Visscher, P. M. (2011). GCTA: A tool for genome-wide complex trait analysis. American Journal of Human Genetics, 88(1), 76-82. https://doi.org/10.1016/j.ajhg.2010.11.011

Young, A. I. (2019). Solving the missing heritability problem. PLOS Genetics, 15(6), e1008222. https://doi.org/10.1371/journal.pgen.1008222

Zheng, A., Briley, D. A., Malanchini, M., Tackett, J. L., Harden, K. P., \& Tucker-Drob, E. M. (2019). Genetic and Environmental Influences on Achievement Goal Orientations Shift with Age. European Journal of Personality, (March). https://doi.org/10.1002/per.2202

Zou, H., \& Hastie, T. (2005). Regularization and variable selection via the elastic net. J.R. Statist. Soc. B, 67(2), $301-320$. 